\title{
Successive translocation of the rings in a [3]rotaxane
}

\author{
Dhiredj C. Jagesar ${ }^{[a]}$ Piet G. Wiering, ${ }^{[a]}$ Euan R. Kay, ${ }^{[\mathrm{b}, \mathrm{c}]}$ David A. \\ Leigh, $^{[\mathrm{b}, \mathrm{d}]}$ Albert M. Brouwer ${ }^{[\mathrm{a}]} *$
}

[a] Dr. D.C. Jagesar, P.G. Wiering, prof. dr. A.M. Brouwer, University of Amsterdam, van 't Hoff Institute for Molecular Sciences, PO Box 94157, 1090 GD Amsterdam, The Netherlands. E-mail a.m.brouwer@uva.nl

[b] Dr. E. R. Kay, Prof. Dr. D. A. Leigh, School of Chemistry, University of Edinburgh, The King's Buildings, West Mains Road Edinburgh, EH9 3JJ, UK

[c] present address: dr. E.R. Kay, EaStCHEM School of Chemistry, University of St Andrews, North Haugh, St Andrews, KY16 9ST, UK

[d] present address: prof. D.A. Leigh, School of Chemistry, The University of Manchester, Oxford Road, Manchester M13 9PL, United Kingdom E-mail: david.leigh@manchester.ac.uk

Keywords: molecular shuttle; rotaxane; molecular muscle; infrared spectroscopy; electrochemistry 


\begin{abstract}
A [2] rotaxane, a [3] rotaxane and the corresponding thread containing two succinamide (succ) binding stations and a central redox-active pyromellitimide $(p m i)$ station were studied. Infrared spectroelectrochemical experiments revealed the translocation of the macrocycle between the succinamide station and the electrochemically reduced pmi station (radical anion and dianion). Remarkably, in the [3] rotaxane, the rings can be selectively translocated. One-electron reduction leads to the translocation of one of the two macrocycles from the succinamide to the pyromellitimide station, while activation of the shuttle via two-electron reduction results in the translocation of both macrocycles: the dianion, due to its higher electron density and hence greater hydrogen bond accepting affinity, is hydrogen-bonded to both macrocycles. Systems with such an on-command contraction are known as molecular muscles. The relative strengths of the binding between the macrocycle and the imide anions could be estimated from the hydrogen bond induced shifts in the $\mathrm{C}=\mathrm{O}$ stretching frequencies of hydrogen bond accepting amide groups of the macrocycle.
\end{abstract}

\title{
Introduction
}

The concept of a "molecular machine" has inspired scientists already for several decades. Thanks to the advancement of synthetic methodology, many different types of molecular machines have been realized. ${ }^{[1-5]}$ Some of these have appealing analogies in the macroscopic world, such as valves ${ }^{[0-8]}$ and muscles. ${ }^{[9-11]}$ Others are better viewed as information processors, ${ }^{[12]}$ or function as single-molecular chemical factories. ${ }^{[13,14]}$ For the design of molecular muscles different approaches have been explored, ${ }^{[15-18]}$ but the use of mechanically interlocked building blocks is advantageous because it allows to put constraints on the relative movements of the components. ${ }^{[19-27]}$ In the present work, we describe the translation of either one or both of the macrocyclic rings in a [3] rotaxane by one-electron or two-electron reduction of a central diimide.

In previous studies in our laboratories, we have investigated the hydrogen bonding interactions between the macrocycle and the binding stations of rotaxanes that are switchable by electron transfer. ${ }^{[28-33]}$ Infrared spectroscopy has proven to be a powerful tool in these studies, because intercomponent interactions lead to specific spectroscopic signatures. ${ }^{[29,34-38]}$

In this paper, the switching in [2] and [3] rotaxanes 2 and $\mathbf{3}$ (Scheme 1) containing a pyromellitimide $(p m \imath)$ station is investigated by means of IR spectroelectrochemistry. The hydrogen bonding between the macrocycle and the reduced aromatic imide station is evaluated in terms of acceptor strength and spatial arrangement of the hydrogen bond accepting $\mathrm{C}=\mathrm{O}$ groups. The binding of the macrocycle to the pmi station will be compared

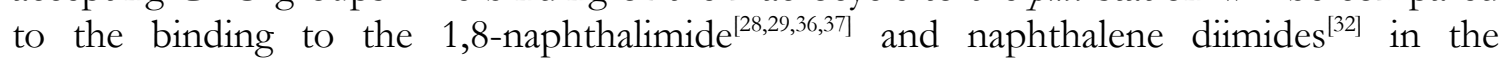
corresponding rotaxanes studied before.

Scheme 1 Structures of thread 1, [2]rotaxane 2 and [3]rotaxane 3 equipped with a pyromellitimide ( $p m i)$ and two succinamide (succ) binding stations. 
The electrochemical behavior of $\mathrm{N}$-substituted pyromellitimides is characterized by two reversible steps (in DMF: $-0.7 \mathrm{~V}$ and $-1.4 \mathrm{~V}$ vs. SCE) corresponding to the formation of the radical anion and the dianion, respectively. ${ }^{\left[3{ }^{3}-4\right]}$ In the reduced species, the additional electrons in the LUMO are stabilized by delocalization of the charge over the carbonyls through the aromatic ring. Compared to the naphthalimide station, the pyromellitimide contains a smaller aromatic core over which the excess electrons are delocalized. This is expected to result in higher electron densities on the carbonyls in the dianion, and hence a larger hydrogen bond accepting affinity compared to the naphthalimide case. On the other hand, the orientation of the $\mathrm{C}=\mathrm{O}$ bonds is slightly different, which may affect the geometric complementarity with the amide donors on the benzylic amide macrocycle.

The macrocycle translocation in the pyromellitic rotaxanes $\mathbf{2}$ and $\mathbf{3}$ has been studied in our laboratory by means of UV-Vis spectroscopy. ${ }^{[32,42]}$ The differences between the electronic absorption spectra of electrochemically generated radical anions and dianions of the [2] rotaxane $\left(\mathbf{2}^{\mathbf{-}}\right.$ and $\left.\mathbf{2}^{\mathbf{2}}\right)$, and thread $\left(\mathbf{1}^{\mathbf{-}}\right.$ and $\left.\mathbf{1}^{\mathbf{2 -}}\right)$ were analyzed. In THF, only a marginal blue-shift $(1 \mathrm{~nm})$ and broadening of the $\mathrm{D}_{0} \rightarrow \mathrm{D}_{1}$ transition $^{[40]}$ at $717 \mathrm{~nm}$ of $\mathbf{2}^{\bullet-}$ relative to $\mathbf{1 0}^{\mathbf{- 1}}$ was observed. The absorption spectrum of the dianion $\mathbf{2}^{2-}$ showed a more pronounced signature of macrocycle translocation: a blue-shift of $17 \mathrm{~nm}(570 \rightarrow 553 \mathrm{~nm})$. Also in this case a band broadening was observed. The changes in the absorption spectra were sufficiently large to allow us to study the dynamics of the shuttling in a time resolved manner with transient absorption spectroscopy. The shifts of the absorption maxima of $\mathbf{2}^{\mathbf{*}}$ and $\mathbf{3}^{-\mathbf{-}}$ relative to thread $\mathbf{1}$, which are caused by hydrogen bonding of the reduced pmi station with the macrocycle, were found to be similar (ca. $4 \mathrm{~nm}$ ). The observed shuttling rate $\left(k_{\text {sisutite }}\right)$ was larger for the [3] rotaxane $\left(k_{\text {sisuttle }}=3.3 \times 10^{-4} \mathrm{~s}^{-1}\right)$ than for the [2] rotaxane $\left(k_{\text {sishutle }}=2.3 \times 10^{-4} \mathrm{~s}^{-1}\right) \cdot{ }^{[32,42]}$

Despite the fact that the change in band shape demonstrates the existence of interactions between the macrocycle and the radical anion of the pyromellitimide chromophore, the small shift could be a sign that the translocation of the macrocyclic ring might not be complete. In other words: a fraction of $\mathbf{2}^{\mathbf{*}}$ could still exist as the co-conformer in which the macrocycle resides at the succinamide station rather than at the reduced pyromellitimide station. The UV-Vis techniques that were used did not allow us to separately detect the two distinct co-conformers. Alternatively, even if shuttling is complete, the hydrogen bond interactions between the macrocycle and the reduced pmi station might be too weak to substantially modify the electronic properties of the latter.

Infrared spectroscopy offers possibilities to complement the results obtained with the UVVis based techniques, because instead of looking at one single chromophore, several IRactive groups involved in the shuttling process can be probed. In particular, the amide groups of the macrocycle and the succinamide station, and the $\mathrm{C}=\mathrm{O}$ stretching modes of the imide stations are exceptionally good probes for the study of hydrogen-bond stabilized conformers ${ }^{[3,3,36-38]}$ The amide $\mathrm{C}=\mathrm{O}$ stretching $[v(C O)]$, often called the Amide I band, and $\mathrm{NH}$ stretching $\left[v(\mathrm{NH})\right.$ frequencies are strongly affected by hydrogen bonds. ${ }^{[4,44]}$ Hydrogen bonding between amide groups decreases the $\mathrm{NH}$ and $\mathrm{C}=\mathrm{O}$ bond orders in both acceptor amide and donor amide. ${ }^{[34,38,45]}$ Therefore, for amides involved in hydrogen bonding, generally a substantial red-shift of the $v(\mathrm{CO})$ and $v(\mathrm{NH})$ frequencies is observed.

In this work, the macrocycle positioning in $\mathbf{2}$ and $\mathbf{3}$ and their radical anions and dianions will be studied with infrared spectroelectrochemistry. The $\mathrm{C}=\mathrm{O}$ stretching frequencies of the macrocycle $\left[v(C O)_{\text {max }}\right.$, the succinamide station $\left[v(C O)_{\text {surc }}\right]$ and the pyromellitimide station $\left[v(C O)_{p m i}\right]$ will be used to identify the co-conformers formed upon electrochemical 
reduction of $\mathbf{2}$ and $\mathbf{3}$ with one and two electrons. An interesting question is whether in the [3] rotaxane one or both macrocycles move to the reduced pyromellitimide station (Scheme 2). The infrared experiments can give more insight into this matter.

Scheme 2 Three different possible co-conformers of 3 resulting from translocation of one or both macrocycles.

\section{Results and Discussion}

\section{Infrared Spectra}

The Amide I regions of the IR spectra of compounds 1, 2, $\mathbf{3}$ and model compound $\mathbf{4}$ are shown in Figure 1A. The spectra were scaled to the intensity of the isolated band at $\sim 1723$ $\mathrm{cm}^{-1}$ in order to facilitate comparison. The IR spectrum of $\mathbf{4}$ contains two bands in the Amide I region: a weak absorption at $1775 \mathrm{~cm}^{-1}$ and a strong one at $1724 \mathrm{~cm}^{-1}$. These spectral features are in agreement with those reported in the literature for $N$-substituted pyromellitimides. ${ }^{[39,46,47]}$ The high frequency band is assigned to the symmetric $\mathrm{C}=\mathrm{O}$ stretching $\left[v_{s}(C O)_{p m i}\right.$, while the low frequency band originates from antisymmetric $\mathrm{C}=\mathrm{O}$ stretching $\left[v_{a s}(C O)_{p m i}\right]$ of the imide as shown in Figure 1 . The assignment of the bands was supported by B3LYP model calculations: two bands at $1776 \mathrm{~cm}^{-1}$ (weak) and $1733 \mathrm{~cm}^{-1}$ (strong) are predicted, which agrees nicely with the experimental result.

Figure 1 Amide I region in the IR spectra of model compound $\mathbf{4}$ and pyromellitimide thread $\mathbf{1}$, [2]rotaxane 2 and [3]rotaxane 3 in THF. The spectra were scaled to the intensity of the $v_{a s}(C O)_{p m i}$ band at $\sim 1723 \mathrm{~cm}^{-1}$ in order to facilitate comparison. Vibrational modes and corresponding wavenumbers of the pyromellitimide model compound 4 .

The $v(C O)$ bands of the pyromellitimide station in $\mathbf{1 , 2}, \mathbf{3}$ are found at 1772 and $1723 \mathrm{~cm}^{-1}$, almost at the same positions as in $\mathbf{4}$. The slight band broadening in 1, $\mathbf{2}$ and $\mathbf{3}$ compared to $\mathbf{4}$ indicates that the model compound $\mathbf{4}$ does not capture all the essential features of the pyromellitic station in 1, 2 and $\mathbf{3}$.

The bands of the pyromellitimide station are well separated from the $v(C O)$ bands of the succinamide station $\left[v(C O)_{\text {suc }}\right]$ and the macrocycle $\left[v(C O)_{\text {mar }}\right.$. In the IR spectrum of thread 1, the characteristic band pattern of the succinamide station appears between 1690 and 1600 $\mathrm{cm}^{-1} \cdot{ }^{[29,37]}$ The strong band at $1677 \mathrm{~cm}^{-1}$ can be assigned to the unperturbed $v(C O)_{\text {succ }}$ mode. The contribution from $\mathrm{C}=\mathrm{O}$ stretching in intramolecularly hydrogen bonded conformations appears on the red side of the main band. A remarkable difference with the band pattern found in a previously studied succinamide model compound ${ }^{[2]}$ is the additional band at $1635 \mathrm{~cm}^{-1}$. This band is assigned to $v(C O)$ modes in folded conformations stabilized by intramolecular hydrogen bonds between the two succinamide stations (Scheme 3). The proposed structure of folded-1 is stabilized by a hydrogen bonding motif which is very similar to the ones responsible for the stabilization of antiparallel $\beta$ sheets and $\beta$-hairpins in many proteins. ${ }^{[48]}$ The succinamide model compound has conformations with hydrogen bonds between the two amides of the succinamide unit. These hydrogen bonds lead to red shifts of $20 \mathrm{~cm}^{-1}$, but the red-shift of the hydrogen bonded $v(C O)_{\text {suc }}$ band of folded-1 $\left(42 \mathrm{~cm}^{-1}\right)$ is significantly larger implying that hydrogen bonding is stronger in folded-1. A reasonable explanation for this difference is that the geometries of the hydrogen bonds in folded-1 are much more favorable than for the intra- 
succinamide hydrogen bonds. Despite this, the relative intensities of the free and hydrogen bonded $\mathrm{C}=\mathrm{O}$ stretching bands suggests that the folded conformations are of minor importance; the extended conformations are predominant.

Scheme 3 Structures of two possible conformations of thread 1: the predominant extended and the minor folded conformations.

In the IR spectrum of [2] rotaxane 2, an additional band is present at $1667 \mathrm{~cm}^{-1}$ which originates form the macrocycle $\mathrm{C}=\mathrm{O}$ stretching $\left[v(C O)_{\text {mac }}\right.$. The free $v(C O)_{\text {suc }}$ band $(1677$ $\left.\mathrm{cm}^{-1}\right)$ is still present as a shoulder on the $v(C O)_{\text {mac }}$ band at $1667 \mathrm{~cm}^{-1}$, but it is less intense than in 1. This is in agreement with our expectation. In 2, one succinamide station is expected to be free, giving rise to free $v(C O)_{\text {succ }}$ bands (as in 1), while the other one is occupied by the macrocycle. The hydrogen-bonded $v(C O)_{\text {suc }}$ band of the occupied succinamide station is red-shifted by $44 \mathrm{~cm}^{-1}$ and appears at $1633 \mathrm{~cm}^{-1}$.

For the [3] rotaxane 3, apart from $v(C O)_{\text {pmi }}$ bands, only two bands are observed in the $1600-$ $1690 \mathrm{~cm}^{-1}$ range of the IR spectrum: the $v(C O)_{\text {mac }}$ band at $1667 \mathrm{~cm}^{-1}$ and the hydrogenbonded $v(C O)$ succ band at $1633 \mathrm{~cm}^{-1}$. The latter is more intense than in $\mathbf{2}$, because in $\mathbf{3}$ both succinamide stations are occupied and hydrogen-bonded to a macrocycle. For the same reason the free $v(C O)_{\text {sum }}$ band is absent. Also, the $v(C O)_{\text {mac }}$ is more intense because 3 contains two macrocycles.

The infrared spectra of the rotaxanes show that in the neutral molecules the macrocycles are practically exclusively located on the succinamide stations. In the ${ }^{1} \mathrm{H}$ NMR spectra (see Experimental Section and reference ${ }^{[32]}$ ) the free succinamide $\mathrm{CH}_{2}$-protons give peaks at $\sim 2.3 \mathrm{ppm}$, while they are shifted to $1.0 \mathrm{ppm}$ when shielded by the macrocycle aromatic rings. The $\mathrm{CH}_{2}$-protons near the imide station resonate at the same chemical shifts in the thread and in the rotaxanes. All these observations indicate a high positional integrity of the molecular shuttles in the neutral form. ${ }^{[32,49]}$

\section{Infrared Spectroelectrochemistry}

\section{Model Compound}

Upon one-electron reduction of $\mathbf{4}$ four new red-shifted strong bands from the radical anion $\left(4^{--}\right)$at $1661,1653,1642$ and $1637 \mathrm{~cm}^{-1}$ grow in at the expense of the bands of the neutral molecule (Figure 2).

Figure 2 Partial IR spectra of the neutral pyromellitimide model compound $4(-)$, radical anion $\mathbf{4}^{\circ-}(\cdots)$ and dianion $\mathbf{4}^{2-}(---)$ in THF.

An isobestic point is detected at $1690 \mathrm{~cm}^{-1}$. This result is in agreement with spectra reported in the literature for an N-butyl substituted pyromellitimide. ${ }^{[39]}$ The fact that the spectrum of 40- contains four bands is surprising, because the B3LYP calculation predicts the presence of only two bands, originating from the $v_{s}(C O)_{p m i}$ mode at $1655 \mathrm{~cm}^{-1}$ and the $v_{a s}(C O)_{p m i}$ mode at $1649 \mathrm{~cm}^{-1}$. The presence of four bands in the experimental spectrum can be explained by Fermi resonance. The phenomenon of Fermi resonance may arise when two vibrational transitions (usually a fundamental and an overtone) possess the same transition energy and symmetry. In such cases of accidental degeneracy, the two modes can mix causing the 
bands to shift apart in energy and share intensity. The weak overtone will gain considerable intensity due to mixing with the strong fundamental and can appear nearly as strong as the fundamental. Instead of observing only one strong band of the fundamental mode and a weak band from the overtone, two nearly equally intense bands may be observed. In the literature, some cases of Fermi resonances with the $\mathrm{C}=\mathrm{O}$ stretching modes in neutral imides have been reported. ${ }^{[50-54]}$ For example, in $N$-substituted phthalimides, both the symmetric and antisymmetric $\mathrm{C}=\mathrm{O}$ stretching vibrations are in resonance with an overtone of an Ar$\mathrm{CO}$ mode, resulting in the splitting of each corresponding $\mathrm{C}=\mathrm{O}$ stretching band into two equally intense bands. ${ }^{[51]}$ So far, examples of Fermi coupling of $\mathrm{C}=\mathrm{O}$ stretching modes of mono- and dianions of aromatic imides have not been reported in literature.

In the case of $\mathbf{4}^{\bullet-}$, splitting of the $v(C O)_{\text {pmi }}$ bands by Fermi resonance with an overtone can only occur if the fundamental of this overtone is at half the wavenumber of the fundamental $v(C O)_{\text {pmi }}$ mode. The wavenumbers of the $v(C O)_{\text {pmi }}$ modes are calculated at 1655 and $1649 \mathrm{~cm}^{-1}$, so the fundamental of the interacting overtone must be at approximately 826 $\mathrm{cm}^{-1}$. The B3LYP calculation indeed predicts a weak band at $827 \mathrm{~cm}^{-1}$, corresponding to a deformation of the pyromellitimide skeleton. In the harmonic approximation, the overtone of this mode will have a wavenumber of $1654 \mathrm{~cm}^{-1}$, which is at almost the same wavenumber as the $v(C O)_{p m i}$ vibrations. Unfortunately, the presence of this band could not be confirmed with the experimental spectra, because of strong absorptions of the electrolyte $\left(\mathrm{NBu}_{4} \mathrm{PF}_{6}\right)$ and solvent (THF) below $1000 \mathrm{~cm}^{-1}$.

The four bands in the spectrum of $\mathbf{4}^{-\mathbf{-}}$ can now be assigned, based on the conclusion that the observed band pattern result from spitting of the unperturbed $v_{s}(C O)_{p m i}$ and $v_{a s}(C O)_{p m i}$ due to Fermi resonance. The first doublet of almost equally intense bands at 1661 and 1653 $\mathrm{cm}^{-1}$ is assigned to the $v_{s}(C O)_{p m i}$ vibration in Fermi resonance with the overtone of the pyromellitimide skeleton deformation. In analogy, the doublet consisting of bands at 1642 and $1637 \mathrm{~cm}^{-1}$ is assigned to the $v_{a s}(C O)_{p m i}$ vibration.

For the dianion $\mathbf{4}^{2-}$, B3LYP calculations predict the presence of three bands: the $v_{s}(C O)_{\text {pmin }}$, the $v_{a s}(C O)_{p m i}$ and an aromatic ring vibration $\left[v(A r)_{p m i}\right.$. Surprisingly, also for the dianion $\mathbf{4}^{2-}$, the experimental spectrum contains more bands. Six new bands are observed: two weak bands at 1713 and $1546 \mathrm{~cm}^{-1}$, and reasonably strong bands at 1669, 1607, 1569 and 1517 $\mathrm{cm}^{-1}$ (Figure 2). Based on the result of the B3LYP calculation, three of these six bands can be assigned: the $v_{s}(C O)_{p m i}$ at $1607 \mathrm{~cm}^{-1}$ (predicted: $1600 \mathrm{~cm}^{-1}$ ) the $v_{a s}(C O)_{p m i}$ at $1569 \mathrm{~cm}^{-1}$ $\left(1570 \mathrm{~cm}^{-1}\right)$ and the $v(A r)_{\text {pmi }}$ at $1517 \mathrm{~cm}^{-1}\left(1521 \mathrm{~cm}^{-1}\right)$. The other three bands $(1713,1669$ and $\left.1546 \mathrm{~cm}^{-1}\right)$ were not predicted by the B3LYP calculation. Therefore, we presume that these bands are due to overtones or Fermi resonance.

\section{Macrocycle Translocation in the Radical Anions}

The IR spectrum of the radical anion of the thread $\left(\mathbf{1}^{-\mathbf{-}}\right.$, Figure $\left.3 \mathrm{~A}\right)$ contains two doublets due to Fermi resonance, belonging to the $v_{s}(C O)_{p m i}\left(1659\right.$ and $\left.1647 \mathrm{~cm}^{-1}\right)$ and the $v_{a s}(C O)_{p m i}$ mode $\left(1641\right.$ and $\left.1631 \mathrm{~cm}^{-1}\right)$. The wavenumbers were obtained after fitting the cluster of four bands to a sum of four Lorentzian peaks. The bands were assigned in analogy to $\mathbf{4}^{\mathbf{*}}$. The average wavenumber of the bands of each doublet, which is an approximation of the wavenumber of the unperturbed vibration, is $1653 \mathrm{~cm}^{-1}$ for the $v_{s}(C O)_{\text {pmi }}$ and $1636 \mathrm{~cm}^{-1}$ for the $v_{a s}(C O)_{\text {pmi }}$ mode. As was the case in the spectra of the neutral molecules, band broadening in $\mathbf{1}^{\bullet-}$ compared to $\mathbf{4}^{\mathbf{}-}$ is also observed. The band patterns, however, are similar for $\mathbf{1}^{\bullet-}$ and $\mathbf{4}^{\bullet-}$. 
Figure 3 Parts of the IR spectra of neutral (-) and radical anion $(\cdots)$ of $(A)$ pyromellitimide thread 1, (B) [2]rotaxane 2 and (C) [3]rotaxane 3 in THF. The spectra of the neutral species were scaled to the intensity of the $v_{a s}(C O)_{p m i}$ band at $\sim 1723 \mathrm{~cm}^{-1}$.

In order to highlight the changes caused by reduction of the pmi unit, the difference spectra of the threads and the rotaxanes, in which the spectra of the neutral forms are subtracted from the spectra of the corresponding radical anions, are displayed in Figure 4. The bands characteristic of the radical anion thus appear as positive, those of the neutral form as negative. When bands are not changed, they cancel, but small shifts are easily seen as narrow features, both positive and negative.

Figure 4 Difference IR spectra (radical anion minus neutral) of thread $1(-)$, [2] rotaxane $2(\cdots)$ and [3]rotaxane 3 (- - ) in THF. The spectra were scaled to the intensity of the $v_{a s}(C O)_{p m i}$ band at $\sim 1723 \mathrm{~cm}^{-1}$ before subtraction.

The difference spectrum of the thread 1 reveals the changes in the vibrations of the pmi unit upon reduction. The major bands are the characteristic ones of the pyromellitimide $\mathrm{C}=\mathrm{O}$ stretching: negative $v(C O)_{\text {pmi }}$ bands of the neutral molecule and the positive $v(C O)_{\text {pmi }}$ bands of the radical anion. Some red-shifted broad bands are observed in the $1500-1610 \mathrm{~cm}^{-1}$ range. These can be ascribed to $v(C O)_{\text {pmi }}$ modes of folded conformations stabilized by hydrogen bonds between the succinamide stations and the reduced pyromellitimide station. Such folded conformations were also detected for the previously studied thread which contained succinamide and naphthalimide stations. ${ }^{[2]]}$ The relative intensities of the unperturbed bands and the red-shifted bands show that the extended conformations are predominant.

The radical anions of the rotaxanes, $\mathbf{2}^{\mathbf{-}}$ and $\mathbf{3}^{\mathbf{-}}$, exhibit a different band pattern compared to that of the thread $\mathbf{1}^{\bullet-}$. The difference spectra of both rotaxanes are strikingly different from that of $\mathbf{1}$, but very similar to each other. Already two important conclusions can be drawn from this observation. First of all, it indicates that a structural change has occurred in both rotaxanes, and secondly: this structural change is the same for both rotaxanes. The only explanation for the difference between the difference spectra of thread and rotaxanes is that macrocycle translocation takes place.

The change of band pattern of the imide $\mathrm{C}=\mathrm{O}$ vibrations is in part due to the absence of the Fermi resonance that splits some bands in $\mathbf{1}^{\mathbf{}}$, but not in the rotaxanes $\mathbf{2}^{\mathbf{-}}$ and $\mathbf{3}^{\mathbf{}}$. The red-shifted bands at 1632 and $1599 \mathrm{~cm}^{-1}$ are attributed to $v_{s}(C O)_{p m i}$ and $v_{a s}(C O)_{p m i}$ modes of the pyromellitimide radical anion which is hydrogen bonded to the macrocycle. This redshift causes a mismatch between the wavenumbers of the $v(C O)_{\text {pmi }}$ modes and the resonant overtone. Consequently, Fermi resonance is no longer possible in $\mathbf{2}^{\mathbf{0}}$ and $\mathbf{3}^{\mathbf{0}}$. The redshifts of the $v_{s}(C O)_{p m i}$ and $v_{a s}(C O)_{p m i}$ bands (21 and $37 \mathrm{~cm}^{-1}$ respectively) compared to the corresponding bands (average of the band wavenumbers of each Fermi doublet) in $\mathbf{1}^{\text {-- }}$ reflect the bond weakening of the pmi carbonyls, caused by hydrogen bonding with the macrocycle.

Macrocycle translocation might be expected to lead to changes in the band pattern as a result of distortion of the symmetry of the reduced station. Upon binding of the macrocycle to one imide group, a redistribution of the electron density of the radical anion is likely to take place that will result in an increase of electron density on the imide group involved in hydrogen bonding. Consequently, the $\mathrm{C}=\mathrm{O}$ bond strengths may change, and the two imide 
groups can be expected to exhibit different $v(\mathrm{CO})_{\text {pmi }}$ frequencies. The hydrogen bonded imide will give rise to red-shifted frequencies compared to the bare radical anion, while blue-shifted frequencies are expected from the free imide. Following this reasoning, additional bands are expected in the spectra of $\mathbf{2}^{\mathbf{2}}$ and $\mathbf{3}^{\mathbf{-}}$. Such blue-shifted bands, however, could not be resolved in the spectra of $\mathbf{2}^{\mathbf{2}^{--}}$and $\mathbf{3}^{\mathbf{*}}$.

A possible hypothesis to explain this unexpected result is that the macrocycle binds to $\mathrm{C}=\mathrm{O}$ groups of opposite sides (chair conformation in Figure 5) rather than the same side (boat conformation) of the diimide. In the chair-type hydrogen bonded complex, the two imide groups are equivalent. The preference of the macrocycle for binding to two imides can be made plausible with the following arguments. By placing the radical anion in the cavity of the macrocycle, the polar radical anion is shielded from the relatively non-polar solvent. Also, apart from stabilization by hydrogen bonds, $\pi-\pi$ interactions between the benzene rings of the radical anion and macrocycle might lead to additional energy minimization. Definitive proof for this hypothesis can however not be provided by our IR method. Theoretical calculations can give more insight into the existence of the different proposed binding modes and the relative energies of the corresponding complexes.

Figure 5 Possible binding modes of the macrocycle to the pmi radical anion in $2^{\bullet-}$.

Further evidence for translocation of the macrocycle is found in the changes of the $\mathrm{C}=\mathrm{O}$ stretching frequencies of the succinamide station and the macrocycle. In the difference spectra of both $\mathbf{2 0}^{--}$and $\mathbf{3}^{\circ-}$, a positive free $v(C O)_{\text {suce }}$ band at $1678 \mathrm{~cm}^{-1}$ is visible. So, the succinamide station is no longer hydrogen bonded to the macrocycle, which is clear evidence that the ring has moved: in the radical anion, the succinamide station is liberated. Remarkably, the intensities of the free $v(C O)_{\text {succ }}$ bands of $\mathbf{3}^{\mathbf{*}}$ and $\mathbf{2}^{\mathbf{*}}$ are very similar. This means that in $\mathbf{3}^{--}$only one succinamide station is liberated i.e. only one macrocycle has moved to the reduced pyromellitimide station, the other macrocycle stays at the succinamide station. So, pmi-succ $\mathbf{3}^{\mathbf{3}^{-}}$is the predominant co-conformer of $\mathbf{3}^{-\boldsymbol{0}}$ (Scheme 2). If both macrocycles of $\mathbf{3}^{-}$- would move to the pyromellitimide station, the intensity of the free $v(C O)_{\text {suc }}$ band of $\mathbf{3}^{-\mathbf{-}}$ would be twice as high than for $\mathbf{2}^{-\mathbf{}}$, because of the presence of two free succinamide stations.

The position switching of only one macrocycle in $\mathbf{3}^{\mathbf{*}}$ indicates that simultaneous binding of both macrocycles to the pmi station does not lead to further energy minimization of the shuttle. In other words, the energy gain by formation of an additional set of hydrogen bonds with the pmi station does not compensate for the loss associated with breaking hydrogen bonds with the succinamide station. So, the affinity of the macrocycle for the singly occupied pmi station in pmi-succ-3-- is lower than for the succinamide station. Apparently, hydrogen bonding on one imide polarizes the pmi radical anion, taking away the driving force for binding on the other side. In the chair binding mode (Figure 5) the pmi radical anion can obviously bind only one ring.

The $\mathrm{C}=\mathrm{O}$ stretching of the macrocycle which is hydrogen-bonded to the pmi radical anion appears at $1664 \mathrm{~cm}^{-1}$ (Figure 3). In the case of the naphthalimide rotaxane, the corresponding band was observed at a lower frequency of $1660 \mathrm{~cm}^{-1} .^{[29]}$ Since shuttling takes place, one expects a negative peak at $1667 \mathrm{~cm}^{-1}$ from the $\mathrm{C}=\mathrm{O}$ stretching in the macrocycle which was originally hydrogen bonded to the succinamide station. The dip between the bands at 1678 and $1659 \mathrm{~cm}^{-1}$ in the difference spectrum in Figure 4 is due to this contribution. The subtraction of the initial $v(C O)_{\text {mac }}$ is also the reason for the distortion of 
the $v(C O)_{\text {succ }}\left(1678 \mathrm{~cm}^{-1}\right)$ band and the red-shifted new $v(C O)_{\text {mac }}$ band.

The absorption between the peaks at $1664 \mathrm{~cm}^{-1}\left[v(C O)_{\text {mac }}\right]$ and $1632 \mathrm{~cm}^{-1}\left[v_{s}(C O)_{\text {pmi }}\right]$ in the

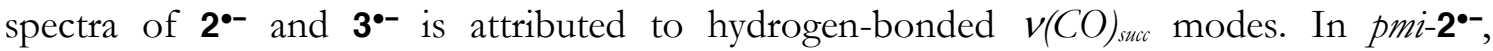
additional hydrogen bonding between the free succinamide stations is possible. These intersuccinamide hydrogen bonds are inhibited in $\mathbf{3}^{\mathbf{0}}$ because one succinamide station remains occupied by a macrocycle. This is clearly evident from the difference spectrum of $\mathbf{3}^{\mathbf{\bullet}}$ : the contribution of hydrogen-bonded $v(C O)_{\text {succ }}$ modes between 1676 and $1659 \mathrm{~cm}^{-1}$ is smaller than in $\mathbf{2}^{-}$. This is the only difference in the difference spectra of the radical anion and neutral forms of $\mathbf{2}$ and $\mathbf{3}$. The assignments of the most important peaks in the spectra of neutral compounds and radical anions are summarized in Table 1.

Table 1 Wavenumbers $\left(\mathrm{cm}^{-1}\right)$ of IR modes in the amide I region of the neutral and radical anions of model compound $\mathbf{4}$, thread $\mathbf{1}$, and rotaxanes $\mathbf{2}$ and $\mathbf{3}$ in THF.

\section{Macrocycle Translocation in the Dianion}

A band pattern similar to that obtained for the dianion of model compound $\mathbf{4}$ can be recognized in the spectrum of $\mathbf{1}^{\mathbf{2}}$ (Figure 6A). Five relatively red-shifted absorption bands from the pmi station are found at 1709, 1659, 1602, 1573 and $1513 \mathrm{~cm}^{-1}$. A counterpart of the weak band of $\mathbf{4}^{2-}$ at $1546 \mathrm{~cm}^{-1}$ is not found in the spectrum of $\mathbf{1}^{2-}$, but it might be shifted and obscured by the broad band at $1573 \mathrm{~cm}^{-1}$ or the Amide II band at $1540 \mathrm{~cm}^{-1}$. The $v(C O)_{\text {suc }}$ band overlaps with the $p m i$ band at $1659 \mathrm{~cm}^{-1}$. The difference spectrum (dianion vs. neutral, Figure 7), contains the expected negative peaks from $v(C O)_{\text {pmi }}$ modes of the neutral molecule. The negative $v(C O)_{\text {suc }}$ peak at $1669 \mathrm{~cm}^{-1}$ represents a decrease of free succ-CO groups in the dianion. This means that compared to $\mathbf{1}$, in $\mathbf{1}^{\mathbf{2}}$ a larger fraction of the succinamide stations is involved in hydrogen bonding, presumably with the two-electron reduced pyromellitimide station in a folded conformation.

Figure 6 Partial IR spectra of the neutral (-) and dianion (- - ) of (A) pyromellitimide thread $\mathbf{1}$, (B) [2] rotaxane 2 and (C) [3] rotaxane 3 in THF. The spectra were scaled to the intensity of the $v_{a s}(C O)_{p m i}$ band of the neutral species at $\sim 1723 \mathrm{~cm}^{-1}$. The band near $1580 \mathrm{~cm}^{-1}$ is due to the electrolyte.

The IR spectra of $\mathbf{2}^{2-}$ and $\mathbf{3}^{2-}$ display more complicated band patterns (Figure 6B and C). In contrast to the case of the radical anions $\mathbf{2}^{-\boldsymbol{D}}$ and $\mathbf{3}^{\mathbf{}}$ - the difference spectra of the dianions $\mathbf{2}^{\mathbf{2 -}}$ and $\mathbf{3}^{\mathbf{2 -}}$ (dianion vs. neutral, Figure 7) are clearly different from each other. Apart from the negative $v(C O)_{\text {pmi }}$ bands, two additional negative peaks at 1669 and $1633 \mathrm{~cm}^{-1}$ are found in the difference spectra. These negative bands are attributed to the $v(C O)_{\text {mac }}$ and hydrogen bonded $v(C O)_{\text {suc }}$ modes, respectively, as in the neutral rotaxane. The decrease of these absorptions clearly indicates that the macrocycle in $\mathbf{2}^{\mathbf{2 -}}$ and $\mathbf{3}^{\mathbf{2 -}}$ is no longer hydrogen bonded to the succinamide station. The increase of the free $v(C O)_{\text {suc }}$ band intensity at 1679 $\mathrm{cm}^{-1}$ supports this conclusion. The $v(C O)_{\operatorname{mac}}$ appears at 1660 and $1661 \mathrm{~cm}^{-1}$ for $\mathbf{2}^{2-}$ and $\mathbf{3}^{2-}$ respectively. In the radical anion, this band was positioned at $1664 \mathrm{~cm}^{-1}$. The additional redshift nicely agrees with stronger hydrogen bonding between macrocycle and the dianion of the pmi station. 
Figure 7 Difference IR spectra (dianion minus neutral) of thread $1(-)$, [2]rotaxane $2(\cdots)$ and [3]rotaxane 3 (- - ) in THF. The spectra were scaled to the intensity of the $v_{a s}(C O)_{p m i}$ band at $\sim 1723 \mathrm{~cm}^{-1}$ before subtraction.

Interestingly, the negative and positive $v(C O)_{\text {suc }}\left(1633\right.$ and $\left.1679 \mathrm{~cm}^{-1}\right)$ and $v(C O)_{\text {mac }}$ bands (1669 and $1658 \mathrm{~cm}^{-1}$ ) are roughly twice as intense in $\mathbf{3}^{\mathbf{2 -}}$ than in $\mathbf{2}^{\mathbf{2 -}}$. This is clear evidence for the existence of co-conformer pmi-pmi-32- (see Scheme 2): in the dianion of the [3]rotaxane both macrocycles are bydrogen-bonded to the reduced pyromellitimide station. As a result, the difference spectra of the dianions $\mathbf{3}^{\mathbf{2}}$ and $\mathbf{2}^{\mathbf{2}}$ are different.

Bands arising from modes located on the reduced pyromellitic station in $\mathbf{2}^{\mathbf{2}-}$ are observed at 1709 , 1648 (shoulder on the $v\left(C O\right.$ ) mac band at $1660 \mathrm{~cm}^{-1}$ ), 1609, 1546 and $1508 \mathrm{~cm}^{-1}$ (Figure 6 and Figure 7). Remarkably, the band at $1609 \mathrm{~cm}^{-1}$ is blue-shifted $7 \mathrm{~cm}^{-1}$ compared to the corresponding band in $\mathbf{1}^{\mathbf{2}}$. The reason for this unexpected blue-shift is uncertain. As was discussed for the radical anion $\mathbf{2 0}^{\mathbf{0}}$, ring translocation might lead to changes in the band pattern as a result of distortion of the symmetry of the reduced pmi station. This is also the case if the chair binding mode prevails (Figure 5).

Despite the fact that the hydrogen-bond induced shifts of the bands in $\mathbf{2}^{\mathbf{2}}$ and $\mathbf{3}^{\mathbf{2}}$ compared to $\mathbf{1}^{\mathbf{2 -}}$ are difficult to resolve, comparison between $\mathbf{2}^{\mathbf{2 -}}$ and $\mathbf{3}^{\mathbf{2 -}}$ is possible because of clear differences in the spectra, specifically in the bands at 1609 and $1549 \mathrm{~cm}^{-1}$. These bands are also present in the spectrum of $\mathbf{3}^{\mathbf{2}}$ but less intense than in that of $\mathbf{2}^{2-}$. And also, additional red-shifted shoulders are observed for $\mathbf{3}^{2-}$ at 1595 and $1538 \mathrm{~cm}^{-1}$. For the pmi-pmi$\mathbf{3}^{2-}$ co-conformer with the structure as sketched in Scheme 2, we would expect two clear bands which are red-shifted compared to the corresponding bands for $\mathbf{2}^{\mathbf{2 -}}$. The observed band pattern of pmi-pmi-32- could mean that the binding mode of the two macrocycles is somewhat different from the one proposed in Scheme 2. It could well be that due to steric hindrance between the two macrocycles, not all eight $\mathrm{N}-\mathrm{H}$ groups of the macrocycles can simultaneously hydrogen-bond to the pyromellitimide radical anion. The assignments and band positions of the major bands of the dianions are listed in Table 2.

Table 2 Wavenumbers $\left(\mathrm{cm}^{-1}\right)$ of IR bands in the amide I region of dianions $4^{2-}, \mathbf{1}^{2-}, \mathbf{2}^{2-}$ and $\mathbf{3}^{2-}$ in THF. The wavenumbers were determined from the spectra in Figure 6. Numbers for the neutral systems are the same as in Table 1 , and are included to facilitate comparison.

\section{Hydrogen Bond Acceptor Strength of the pmi Station}

The co-conformer distribution in the reduced states of aromatic imide based rotaxanes is determined by the driving force for the translation of the ring. This driving force can be related to the reduction potential of the aromatic imides based on the following arguments. The electron affinity and thus reduction potential of aromatic monoimides and diimides depends on the size of the aromatic core and the number of imide groups over which the excess electron can be delocalized. ${ }^{[39]}$ In our aromatic monoimide and diimide rotaxanes, this delocalization determines the electron density on the hydrogen bond accepting carbonyl groups. The larger hydrogen bond affinity of the reduced aromatic imide station compared to that of the succinamide station provides the driving force for the shuttling process in the rotaxanes that we have studied. We may expect that the reduction potential is a good measure for the driving force responsible for the shuttling process because the more delocalized the charge is in the radical anion, the easier it will be to reduce the compound and the lower will be the charge density on the carbonyl groups that accept hydrogen bonds 
from the macrocycle. For aromatic imide compounds, the potential for the first electron reduction shifts to more positive values in the following order: 1,8-naphthalimide < pyromellitimide $<$ naphthalene diimide $<$ perylene diimide. ${ }^{[39-41,55]}$ Consequently, in this series the driving force for macrocycle translocation is expected to decrease. In the case of the naphthalimide $(n i)$-based shuttle it was concluded that activation by one-electron reduction, either electrochemically or photochemically, results in a quantitative conversion to the shuttled co-conformer. ${ }^{[28,29,49]}$ Also in the naphthalene diimide system $(n d i)$, which has a smaller driving force than the mono-imide system, the shuttling in the radical anion was found to be close to complete $(>80 \%) .{ }^{[32]}$ These results suggest that macrocycle translocation in the pyromellitimide based rotaxanes will be close to quantitative as well, because the driving force will be larger than for the naphthalene diimide system. The results for $\mathbf{2}^{\mathbf{*}}$ and $\mathbf{3}^{\mathbf{*}}$ are in agreement with this expectation.

The red-shifts of the $v_{s}(C O)_{p m i}\left(21 \mathrm{~cm}^{-1}, 1653 \mathrm{~cm}^{-1} \rightarrow 1632 \mathrm{~cm}^{-1}\right)$ and $v_{a s}(C O)_{p m i}\left(37 \mathrm{~cm}^{-1}\right.$, $1636 \mathrm{~cm}^{-1} \rightarrow 1599 \mathrm{~cm}^{-1}$ ) frequencies of $\mathbf{2}^{\bullet-}$ and $\mathbf{3}^{\bullet-}$ are larger on average than was observed for the naphthalimide rotaxane $\left(1616 \mathrm{~cm}^{-1} \rightarrow 1591 \mathrm{~cm}^{-1} \text { and } 1565 \mathrm{~cm}^{-1} \rightarrow 1551 \mathrm{~cm}^{-1}\right)^{[29]}$. This suggests that hydrogen bonding with the radical anion of the imide station is stronger in the pyromellitimide rotaxanes. However, the difference in geometry and thus electron distributions of the pyromellitic and naphthalimide station makes this conclusion premature. A more reliable observable for the comparison of hydrogen bond accepting affinities of different imide stations, is the red-shift of the macrocycle $\mathrm{C}=\mathrm{O}$ stretching upon binding to the imide anion. In the radical anion of the naphthalimide rotaxane, a red-shift of $7 \mathrm{~cm}^{-1}$ was observed $\left(1667 \mathrm{~cm}^{-1} \rightarrow 1660 \mathrm{~cm}^{-1}\right)$. For $\mathbf{2}^{\mathbf{-}}$ and $\mathbf{3}^{\mathbf{\bullet}}$, this red-shift is significantly smaller: $3 \mathrm{~cm}^{-1}\left(1667 \mathrm{~cm}^{-1} \rightarrow 1664 \mathrm{~cm}^{-1}\right)$. This difference shows that hydrogen bonding of the macrocycle with the pyromellitimide radical anion is weaker than with the naphthalimide radical anion, as anticipated above.

For the dianions $\mathbf{2}^{2-}$ and $\mathbf{3}^{2-}$ on the other hand, the red-shifts of the $v(C O)_{\text {mac }}$ are similar to the one observed for the radical anion of the ni-shuttle. This result demonstrates that hydrogen bonding with the macrocycle is comparably strong in $\mathbf{2}^{\mathbf{2 -}}, \mathbf{3}^{\mathbf{2 -}}$ and the radical anion of the $n i$-shuttle.

As we noted earlier, the rate of the macrocycle translation in the photochemically generated radical anions of the pmi rotaxanes is smaller than that in the corresponding naphthalimide and naphthalene diimide rotaxanes: $k_{\text {shuttle }}(p m i)<k_{\text {shuttle }}(n d i) \leq k_{\text {sbuttle }}(n i)$. This shows that the strengths of binding to the final station are not decisive for the rate of the shuttling process. This is understandable if the transition structures for the $p m i^{-0}$ system are different from those for the $n i^{\bullet-}$ and $n d i^{\bullet-}$ stations, which is likely to be the case for the "chair"-type binding suggested in Figure 5.

\section{Conclusion}

Infrared spectroelectrochemical experiments with [2] rotaxane $\mathbf{2}$ and [3] rotaxane $\mathbf{3}$ containing two succinamide (succ) stations and a redox-active pyromellitimide ( $p m \imath$ ) binding station revealed the shuttling of the macrocycle between the succ station and the oneelectron and two-electron reduced pmi station (that is, in the radical anion and dianion states, respectively).

The evidence for ring translocation was found in the signatures of hydrogen bonding between amides: hydrogen bonds of the macrocycle $\mathrm{NH}$ groups with the carbonyls of the succ station are broken, which leads to $\mathrm{C}=\mathrm{O}$ stretching frequencies characteristic for unperturbed carbonyls. Complementary to this, formation of hydrogen bonds with the carbonyls of the electrochemically activated pyromellitimide station leads to hydrogen-bond 
induced shifts of the corresponding carbonyl stretching frequencies.

Splitting of the $v(C O)_{p m i}$ bands of the radical anions of thread $\mathbf{1}$ and model compound $\mathbf{4}$ could be traced back to Fermi resonance with an overtone vibration. In the radical anions of the rotaxanes $\mathbf{2}$ and $\mathbf{3}$, red-shifts of the $v(C O)_{p m i}$ frequencies induced by hydrogen bonding with the macrocycle, resulted in distuption of the Fermi resonance.

In the [3] rotaxane $\mathbf{3}$, the macrocycle position can be switched selectively. The radical anion of the pmi station is occupied by only one of the two available macrocycles. Activation of the shuttle with two electrons on the other hand, results in the translocation of both macrocycles: the dianion, due to its higher electron density and hence greater hydrogen bond accepting affinity, is hydrogen-bonded to both macrocycles.

The controlled switching of the position of the two rings is demonstrated here for the first time in a hydrogen-bond based rotaxane. "Molecular muscles" based on rotaxane architectures based on different types of interactions have been described in the literature. $[19,21,22,5,5,57]$ In these reported systems, the contraction is achieved by switching of the rings. Rotaxane $\mathbf{3}$ can be used as the starting point for the design of systems with molecular muscle functionality, for example similar to the one described by Liu et al ${ }^{[2]]}$ By the translocation of the rings, the distance between the rings is reduced. In addition, the possibility of selective translocation of the rings in $\mathbf{3}$ might function as the basic principle for delivering two consecutive contractions, simply by activation with one or two electrons.

The strengths of the hydrogen bonding interactions between the reduced imide stations and the macrocycle could be estimated from the red-shifts of the $v(C O)_{\text {mac }}$ band. It was concluded that compared to the naphthalimide radical anion, the radical anion of the $p m i$ station exhibits lower hydrogen bond affinity towards the macrocycle. The pmi dianion on the other hand, binds to the macrocycle with a similar strength as the naphthalimide radical anion.

\section{Experimental Details}

\section{Synthesis}

The synthesis and characterization of the thread $\mathbf{1}$ and the five-component clipping reaction to obtain rotaxanes $\mathbf{2}$ and $\mathbf{3}$ was described before. ${ }^{[32]}$ In the present work we report the characterization of $\mathbf{3}$, which was not used in the previous study. The pyromellitimide model compound 4 was synthesized through condensation of pyromellitic anhydride and neopentylamine in DMF with 58\% isolated yield using the procedure described below.

\section{2,6-dineopentylpyrrolo[3,4- $f$ isoindole-1,3,5,7(2H,6H)-tetraone}

A solution of pyromellitic anhydride $(0.72 \mathrm{~g}, 2.56 \mathrm{mmol})$ and neopentylamine $(2.8 \mathrm{~g}, 32.2$ $\mathrm{mmol})$ in DMF $(20 \mathrm{~mL})$ was refluxed for 3 days. A white precipitate was formed. The reaction mixture was poured into $\mathrm{H}_{2} \mathrm{O}(50 \mathrm{~mL})$ and the white powder was separated through filtration. The powder was dissolved in $\mathrm{CH}_{2} \mathrm{Cl}_{2}(20 \mathrm{~mL})$ and washed with $1 \mathrm{M} \mathrm{HCl}$ $(3 \times 10 \mathrm{~mL}), \mathrm{H}_{2} \mathrm{O}(3 \times 10 \mathrm{ml})$ and brine $(3 \times 10 \mathrm{~mL})$. The organic layer was dried over $\mathrm{MgSO}_{4}$ and the solvent was evaporated, affording the crude 4 . The crude product was crystallized from ethyl acetate as white platelets. Yield: $0.53 \mathrm{~g}(58 \%) .{ }^{1} \mathrm{H}$ NMR $(400 \mathrm{MHz}$, $\left.\mathrm{CDCl}_{3}\right): \delta=8.31$ (s, $2 \mathrm{H}$, aromatic $\left.\mathrm{H}\right), 3.59\left(\mathrm{~s}, 4 \mathrm{H}, \mathrm{N}-\underline{\mathrm{CH}}_{2}-\mathrm{C}\right), 1.01\left(\mathrm{~s}, 18 \mathrm{H}, \mathrm{C}-\underline{\mathrm{CH}}_{3}\right)$.

[2]-(1,7,14,20-Tetraaza-2,6,15,19-tetraoxo-3,5,9,12,16,18,22,25tetrabenzocyclohexacosane)-[ $N, N^{\prime}$-bis(12-\{[4-(2,2-diphenylethylamino)-4- 
oxobutanoyl]amino\} dodecyl)-pyromellitic diimide]-rotaxane (2) and

[3]-Bis(1,7,14,20-tetraaza-2,6,15,19-tetraoxo-3,5,9,12,16,18,22,25tetrabenzocyclohexacosane)-[N,N'-bis(12-\{[4-(2,2-diphenylethylamino)-4oxobutanoyl]amino\} dodecyl)-pyromellitic diimide]-rotaxane (3)

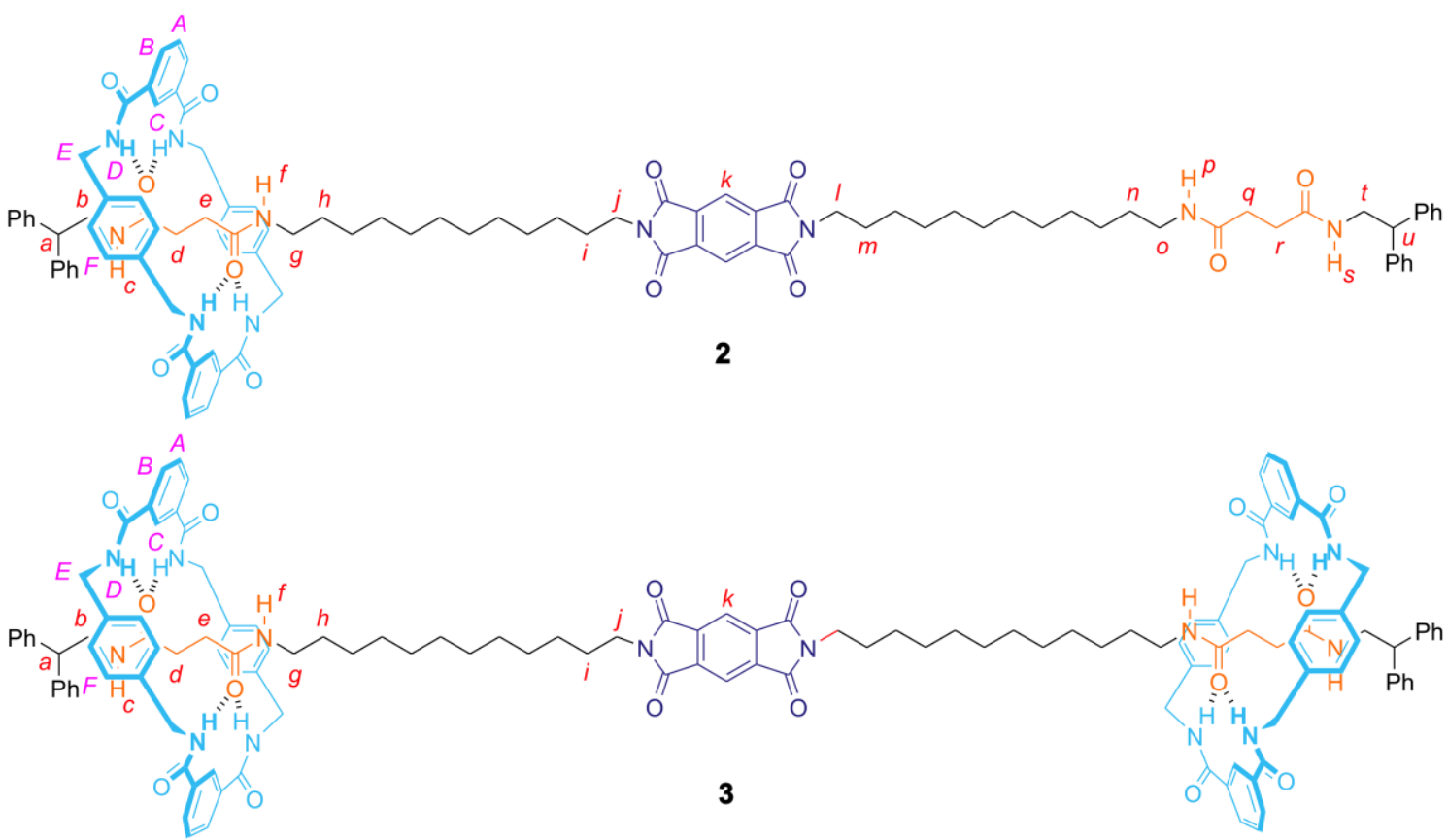

Solutions of isophthaloyl dichloride $(271 \mathrm{mg}, 1.34 \mathrm{mmol})$ in chloroform $(10 \mathrm{~mL})$ and $p$ xylylenediamine $(182 \mathrm{mg}, 1.34 \mathrm{mmol})$ with triethylamine $(375 \mu \mathrm{L}, 2.67 \mathrm{mmol})$ in chloroform $(10 \mathrm{~mL})$ were simultaneously added using motor-driven syringe pumps over $4 \mathrm{~h}$ to a solution of thread $1(190 \mathrm{mg}, 0.167 \mathrm{mmol})$ in chloroform $(25 \mathrm{~mL})$. Following addition, the mixture was allowed to stir for a further $16 \mathrm{~h}$ before removal of the off-white precipitate by filtration. The resulting filtrate was concentrated under reduced pressure and the crude product purified by repeated flash chromatography $\left(\mathrm{SiO}_{2} ; 2: 45: 50\right.$ methanol/ethyl acetate/dichloromethane) to afford, in order of elution:

[3] rotaxane 3 as a colourless solid (15.0 mg, 4.1\%); mp > $140{ }^{\circ} \mathrm{C}$ (decomp.); ${ }^{1} \mathrm{H}$ NMR (400 $\left.\mathrm{MHz}_{\mathrm{CDCl}}\right): \delta=8.25\left(\mathrm{~s}, 4 \mathrm{H}, \mathrm{H}_{\mathrm{C}}\right), 8.11\left(\mathrm{~s}, 2 \mathrm{H}, \mathrm{H}_{\mathrm{k}}\right), 8.08\left(\mathrm{~d}, J=7.6 \mathrm{~Hz}, 8 \mathrm{H}, \mathrm{H}_{B}\right), 7.63(\mathrm{br} \mathrm{s}$, $\left.8 \mathrm{H}, \mathrm{H}_{D}\right), 7.54\left(\mathrm{t}, J=7.6 \mathrm{~Hz}, 4 \mathrm{H}, \mathrm{H}_{A}\right), 7.30-7.15\left(\mathrm{~m}, 20 \mathrm{H}, \mathrm{H}_{P b}\right), 7.07$ (s, 16H, $\left.\mathrm{H}_{\mathrm{F}}\right), 6.70$ (br t, $\left.2 \mathrm{H}, \mathrm{H}_{f}\right), 6.55$ (br t, $\left.2 \mathrm{H}, \mathrm{H}_{c}\right), 4.51-4.43\left(\mathrm{~m}, 16 \mathrm{H}, \mathrm{H}_{E}\right), 4.11$ (br t, $\left.2 \mathrm{H}, \mathrm{H}_{a}\right), 3.74-3.71(\mathrm{~m}, 8 \mathrm{H}$, $\mathrm{H}_{b} \& \mathrm{H}_{j}$ ), 3.01 (br s, 4H, $\mathrm{H}_{g}$ ), 1.68 (br s, 4H, $\left.\mathrm{H}_{i}\right), 1.39$ (br s, 4H, $\left.\mathrm{H}_{b}\right), 1.28-1.16$ (m, 32H, alkyl $\mathrm{CH}_{2}$ ), 1.01-0.99 (m, 8H, $\left.\mathrm{H}_{d} \& \mathrm{H}_{e}\right) ;{ }^{13} \mathrm{C}$ NMR (100 MHz, $\left.\mathrm{CDCl}_{3}\right): \delta=173.1$ (succinamide $\mathrm{C}=\mathrm{O}$ ), 172.9 (succinamide $\mathrm{C}=\mathrm{O}$ ), 166.42 (macrocycle or imide $\mathrm{C}=\mathrm{O}$ ), 166.40 (macrocycle or imide $\mathrm{C}=\mathrm{O}$ ), 141.5 (phenyl $\mathrm{ArC}_{\mathrm{q}}$ ), 137.5 (xylyl $\mathrm{C}_{\mathrm{q}}$ ), 137.1 (pyromellitic $\mathrm{ArC}_{\mathrm{q}}$ ), 133.7 (isophthaloyl $\left.\mathrm{ArC}_{\mathrm{q}}\right), 131.5\left(\mathrm{ArCH}_{B}\right), 129.2\left(\mathrm{ArCH}_{F}\right), 129.0\left(\mathrm{ArCH}_{A}\right), 128.9$ (phenyl $\left.\mathrm{ArCH}\right)$, 127.8 (phenyl ArCH), 127.1 (phenyl $\mathrm{ArCH}), 124.0\left(\mathrm{ArCH}_{C}\right), 117.8\left(\mathrm{ArCH}_{k}\right), 50.5\left(\mathrm{CH}_{a}\right)$, $44.8\left(\mathrm{CH}_{2(b)}\right), 44.0\left(\mathrm{CH}_{2(\mathrm{E})}\right), 39.8\left(\mathrm{CH}_{2(g)}\right), 38.9\left(\mathrm{CH}_{2())}\right), 29.7\left(\mathrm{CH}_{2}\right), 29.5\left(\mathrm{CH}_{2}\right), 29.4\left(\mathrm{CH}_{2}\right)$, $29.3\left(\mathrm{CH}_{2}\right), 29.22\left(\mathrm{CH}_{2}\right), 29.19\left(\mathrm{CH}_{2}\right), 29.1\left(\mathrm{CH}_{2}\right), 28.8\left(\mathrm{CH}_{2}\right), 28.1\left(\mathrm{CH}_{2}\right), 27.3\left(\mathrm{CH}_{2}\right), 26.9$ $\left(\mathrm{CH}_{2}\right), 26.4\left(\mathrm{CH}_{2}\right)$; HRMS (FAB, THIOG matrix): $m / z=2207.1038\left[(\mathrm{M}+\mathrm{H})^{+}\right]$(anal. calcd for $\left.{ }^{12} \mathrm{C}_{133}{ }^{13} \mathrm{CH}_{145} \mathrm{~N}_{14} \mathrm{O}_{16}{ }^{+}: m / z=2207.0997\right)$;

[2] rotaxane 2 as a colourless solid (114 mg, 41\%). The spectroscopic characterization of 2 was reported in ref. ${ }^{[32]}$.

The IR spectra were recorded on a Bruker Vertex 70 FTIR spectrometer. For further details of sample preparation and spectroelectrochemical experiments, see reference ${ }^{[29]}$. For the 
B3LYP calculations of the $\mathrm{C}=\mathrm{O}$ vibrations in $\mathbf{4}$, the neopentyl group was replaced by an ethyl group. In the present work, the $6-31 \mathrm{G}+(\mathrm{d})$ basis set was used. The harmonic frequencies were scaled by a factor $0.9738 .{ }^{[58]}$

\section{Acknowledgement}

This research was financially supported by the Netherlands Organization for the Advancement of Research (NWO).

\section{References}

[1] S. Erbas-Cakmak, D. A. Leigh, C. T. McTernan, A. L. Nussbaumer, Chem. Rev. 2015, 115, 10081-10206.

[2] E. R. Kay, D. A. Leigh, Angew. Chem. Int. Edit. 2015, 54, 10080-10088.

[3] M. Xue, Y. Yang, X. Chi, X. Yan, F. Huang, Chem. Rev. 2015, 115, 7398-7501.

[4] S. Durot, V. Heitz, A. Sour, J.-P. Sauvage, in Topics in Current Chemistry (Eds.: A. Credi, S. Silvi, M. Venturi), Springer Verlag, Berlin/Heidelberg, 2014, pp. 35-70.

[5] S. F. M. van Dongen, S. Cantekin, J. A. A. W. Elemans, A. E. Rowan, R. J. M. Nolte, Chem. Soc. Rev. 2014, 43, 99-122.

[6] J. Croissant, A. Chaix, O. Mongin, M. Wang, S. Clément, L. Raehm, J.-O. Durand, V. Hugues, M. Blanchard-Desce, M. Maynadier, A. Gallud, M. Gary-Bobo, M. Garcia, J. Lu, F. Tamanoi, D. P. Ferris, D. Tarn, J. I. Zink, Small 2014, 10, 17521755.

[7] S. Saha, K. C. F. Leung, T. D. Nguyen, J. F. Stoddart, J. I. Zink, Adv. Funct. Mater. 2007, 17, 685-693.

[8] R. Hernandez, H.-R. Tseng, J. W. Wong, J. F. Stoddart, J. I. Zink, J. Am. Chem. Soc. 2004, 126, 3370-3371.

[9] C. J. Bruns, J. F. Stoddart, Acc. Chem. Res. 2014, 47, 2186-2199.

[10] Z. Zhang, C. Han, G. Yu, F. Huang, Chem. Sci. 2012, 3, 3026-3031.

[11] L. Gao, Z. Zhang, B. Zheng, F. Huang, Polym. Chem. 2014, 5, 5734-5739.

[12] A. Carlone, S. M. Goldup, N. Lebrasseur, D. A. Leigh, A. Wilson, J. Am. Chem. Soc. 2012, 134, 8321-8323.

[13] G. De Bo, S. Kuschel, D. A. Leigh, B. Lewandowski, M. Papmeyer, J. W. Ward, J. Am. Chem. Soc. 2014, 136, 5811-5814.

[14] B. Lewandowski, G. De Bo, J. W. Ward, M. Papmeyer, S. Kuschel, M. J. Aldegunde, P. M. E. Gramlich, D. Heckmann, S. M. Goldup, D. M. D’Souza, A. E. Fernandes, D. A. Leigh, Science 2013, 339, 189-193.

[15] Q. Li, G. Fuks, E. Moulin, M. Maaloum, M. Rawiso, I. Kulic, J. T. Foy, N. Giuseppone, Nat. Nano. 2015, 10, 161-165.

[16] F. Niess, V. Duplan, C. S. Diercks, J.-P. Sauvage, Chem. Eur. J. 2015, 21, 14393 14400.

[17] T. A. Singleton, K. S. Ramsay, M. M. Barsan, I. S. Butler, C. J. Barrett, J. Phys. Chem. B 2012, 116, 9860-9865.

[18] D. Bléger, T. Liebig, R. Thiermann, M. Maskos, J. P. Rabe, S. Hecht, Angew. Chem. Int. Edit. 2011, 50, 12559-12563.

[19] J.-P. Collin, C. Dietrich-Buchecker, P. Gavina, M. C. Jimenez-Molero, J.-P. Sauvage, Acc. Chem. Res. 2001, 34, 477-487.

[20] M. C. Jimenez-Molero, C. Dietrich-Buchecker, J.-P. Sauvage, Chem. Eur. J. 2002, 8, 
1456-1466.

[21] Y. Liu, A. H. Flood, P. A. Bonvallet, S. A. Vignon, B. H. Northrop, H.-R. Tseng, J. O. Jeppesen, T. J. Huang, B. Brough, M. Baller, S. Magonov, S. D. Solares, W. A. Goddard, C.-M. Ho, J. F. Stoddart, J. Am. Chem. Soc. 2005, 127, 9745-9759.

[22] R. E. Dawson, S. F. Lincoln, C. J. Easton, Chem. Commun. 2008, 3980-3982.

[23] G. Du, E. Moulin, N. Jouault, E. Buhler, N. Giuseppone, Angew. Chem. Int. Edit. 2012, 51, 12504-12508.

[24] X. Yan, B. Zheng, F. Huang, Polym. Chem. 2013, 4, 2395-2399.

[25] H. Li, X. Li, Y. Wu, H. Ågren, D.-H. Qu, J. Org. Chem. 2014, 79, 6996-7004.

[26] G. Ragazzon, M. Baroncini, S. Silvi, M. Venturi, A. Credi, Beilstein J. Nanotechnol. 2015, 6, 2096-2104.

[27] Y.-L. Zhao, R.-Q. Zhang, C. Minot, K. Hermann, M. A. Van Hove, Phys. Chem. Chem. Phys. 2015, 17, 18318-18326.

[28] A. M. Brouwer, C. Frochot, F. G. Gatti, D. A. Leigh, L. Mottier, F. Paolucci, S. Roffia, G. W. H. Wurpel, Science 2001, 291, 2124-2128.

[29] D. C. Jagesar, F. Hartl, W. J. Buma, A. M. Brouwer, Chem. Eur. J. 2008, 14, 1935 1946.

[30] D. C. Jagesar, S. M. Fazio, J. Taybi, E. Eiser, F. G. Gatti, D. A. Leigh, A. M. Brouwer, Adv. Funct. Mater. 2009, 19, 3440-3449.

[31] D. D. Günbaş, L. Zalewski, A. M. Brouwer, Chem. Commun. 2010, 46, 2061-2063.

[32] J. Baggerman, N. Haraszkiewicz, P. G. Wiering, G. Fioravanti, M. Marcaccio, F. Paolucci, E. R. Kay, D. A. Leigh, A. M. Brouwer, Chem. Eur. J. 2013, 19, 55665577.

[33] M. R. Panman, B. H. Bakker, D. den Uyl, E. R. Kay, D. A. Leigh, W. J. Buma, A. M. Brouwer, J. A. J. Geenevasen, S. Woutersen, Nat. Chem. 2013, 5, 929-934.

[34] W. Reckien, B. Kirchner, S. D. Peyerimhoff, J. Phys. Chem. A 2006, 110, 12963 12970.

[35] P. Bodis, M. R. Panman, B. H. Bakker, A. Mateo-Alonso, M. Prato, W. J. Buma, A. M. Brouwer, E. R. Kay, D. A. Leigh, S. Woutersen, Acc. Chem. Res. 2009, 42, 14621469.

[36] M. R. Panman, P. Bodis, D. J. Shaw, B. H. Bakker, A. C. Newton, E. R. Kay, A. M. Brouwer, W. J. Buma, D. A. Leigh, S. Woutersen, Science 2010, 328, 1255-1258.

[37] M. R. Panman, P. Bodis, D. J. Shaw, B. H. Bakker, A. C. Newton, E. R. Kay, D. A. Leigh, W. J. Buma, A. M. Brouwer, S. Woutersen, Phys. Chem. Chem. Phys. 2012, 14, 1865-1875.

[38] B. Kirchner, C. Spickermann, W. Reckien, C. A. Schalley, J. Am. Chem. Soc. 2010, 132, 484-494.

[39] A. Viehbeck, M. J. Goldberg, C. A. Kovac, J. Electrochem. Soc. 1990, 137, 1460-1466.

[40] D. Gosztola, M. P. Niemczyk, W. Svec, A. S. Lukas, M. R. Wasielewski, J. Phys. Chem. A 2000, 104, 6545-6551.

[41] T. Iijima, S. A. Vignon, H. R. Tseng, T. Jarrosson, J. K. M. Sanders, F. Marchioni, M. Venturi, E. Apostoli, V. Balzani, J. F. Stoddart, Chem. Eur. J. 2004, 10, 63756392.

[42] J. Baggerman, Photoactive Hydrogen Bonded Rotaxanes, Ph.D. Thesis, Universiteit van Amsterdam, 2006.

[43] P. Bruni, E. Giorgini, E. Maurelli, G. Tosi, Vib. Spectrosc. 1996, 12, 249-255.

[44] G. P. Dado, S. H. Gellman, J. Am. Chem. Soc. 1992, 114, 3138-3139.

[45] W. Herrebout, K. Clou, H. O. Desseyn, N. Blaton, Spectrochim. Acta A 2003, 59, 47-59.

[46] T. Schulzet, A. K. Saini, D. Labreque, H. H. Patterson, J. Macromol. Sci. A 1997, 34, 
1535-1552.

[47] A. K. Mishra, D. K. Chattopadhyay, B. Sreedhar, K. V. S. N. Raju, Prog. Org. Coat. 2006, 55, 231-243.

[48] M. S. Searle, J. Chem. Soc., Perkin Trans. 2 2001, 1011-1020.

[49] A. Altieri, F. G. Gatti, E. R. Kay, D. A. Leigh, D. Martel, F. Paolucci, A. M. Z. Slawin, J. K. Y. Wong, J. Am. Chem. Soc. 2003, 125, 8644-8654.

[50] R. A. Nyquist, S. L. Fiedler, Vib. Spectrosc. 1995, 8, 365-386.

[51] D. Likhatchev, S. Granados-Fócil, R. Gaviño, M. Canseco, L. Alexandrova, High Perform. Polym. 1999, 11, 405-415.

[52] A. M. A. Pistorius, P. J. T. A. Groenen, W. J. de Grip, Int. J. Pept. Protein Res. 1993, 42, 570-577.

[53] M. C. Delvaux-de Wilde, T. Zeegers-Huyskens, Spectrosc. Lett. 1979, 12, 7-16.

[54] D. Likhatchev, L. Valle, M. Canseco, R. Salcedo, R. Gaviño, A. Martinez-Richa, L. Alexandrova, R. Vera-Graziano, J. Appl. Polym. Sci. 1998, 67, 609-619.

[55] D. G. Hamilton, M. Montalti, L. Prodi, M. Fontani, P. Zanello, J. K. M. Sanders, Chem. Eur. J. 2000, 6, 608-617.

[56] C. J. Chuang, W. S. Li, C. C. Lai, Y. H. Liu, S. M. Peng, I. Chao, S. H. Chiu, Org. Lett. 2009, 11, 385-388.

[57] C.-J. Chuang, C.-C. Lai, Y.-H. Liu, S.-M. Peng, S.-H. Chiu, Chem. Eur. J. 2012, 18, 16698-16707.

[58] M. P. Andersson, P. Uvdal, J. Phys. Chem. A 2005, 109, 2937-2941. 

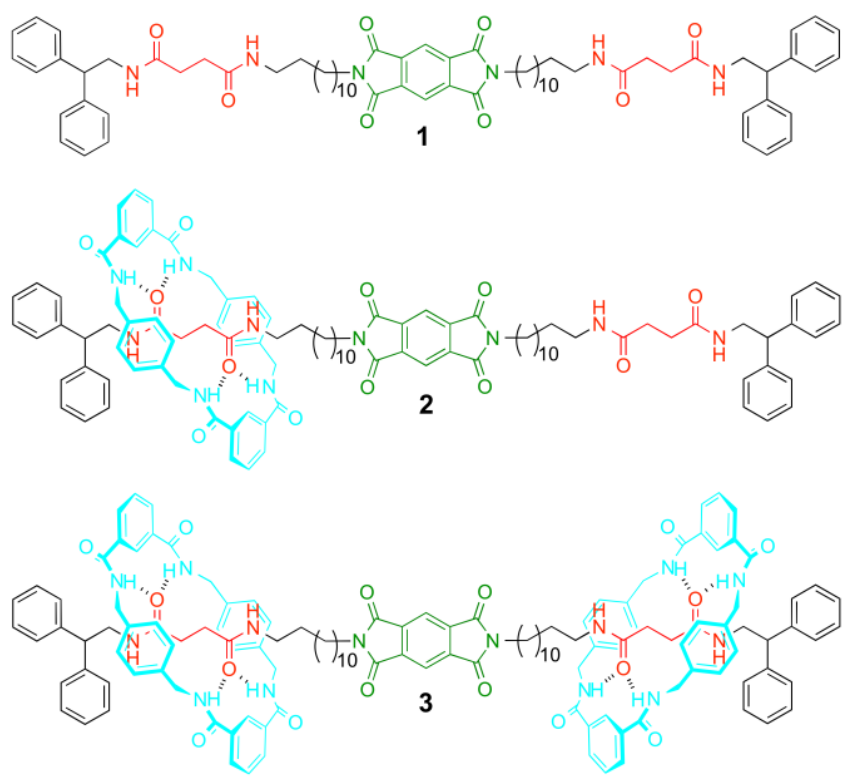

Scheme 1 Structures of thread 1, [2]rotaxane 2 and [3]rotaxane $\mathbf{3}$ equipped with a pyromellitimide (pmi) and two succinamide (succ) binding stations. 

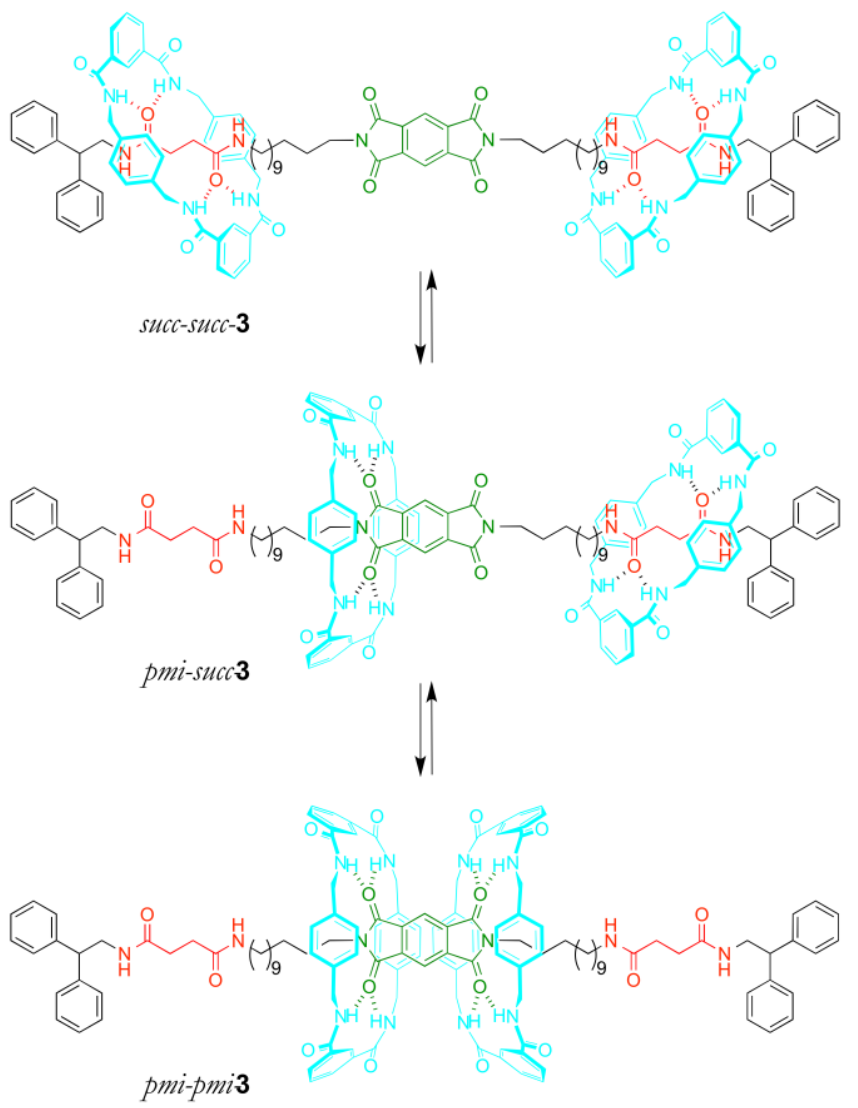

Scheme 2 Three different possible co-conformers of $\mathbf{3}$ resulting from translocation of one or both macrocycles. 

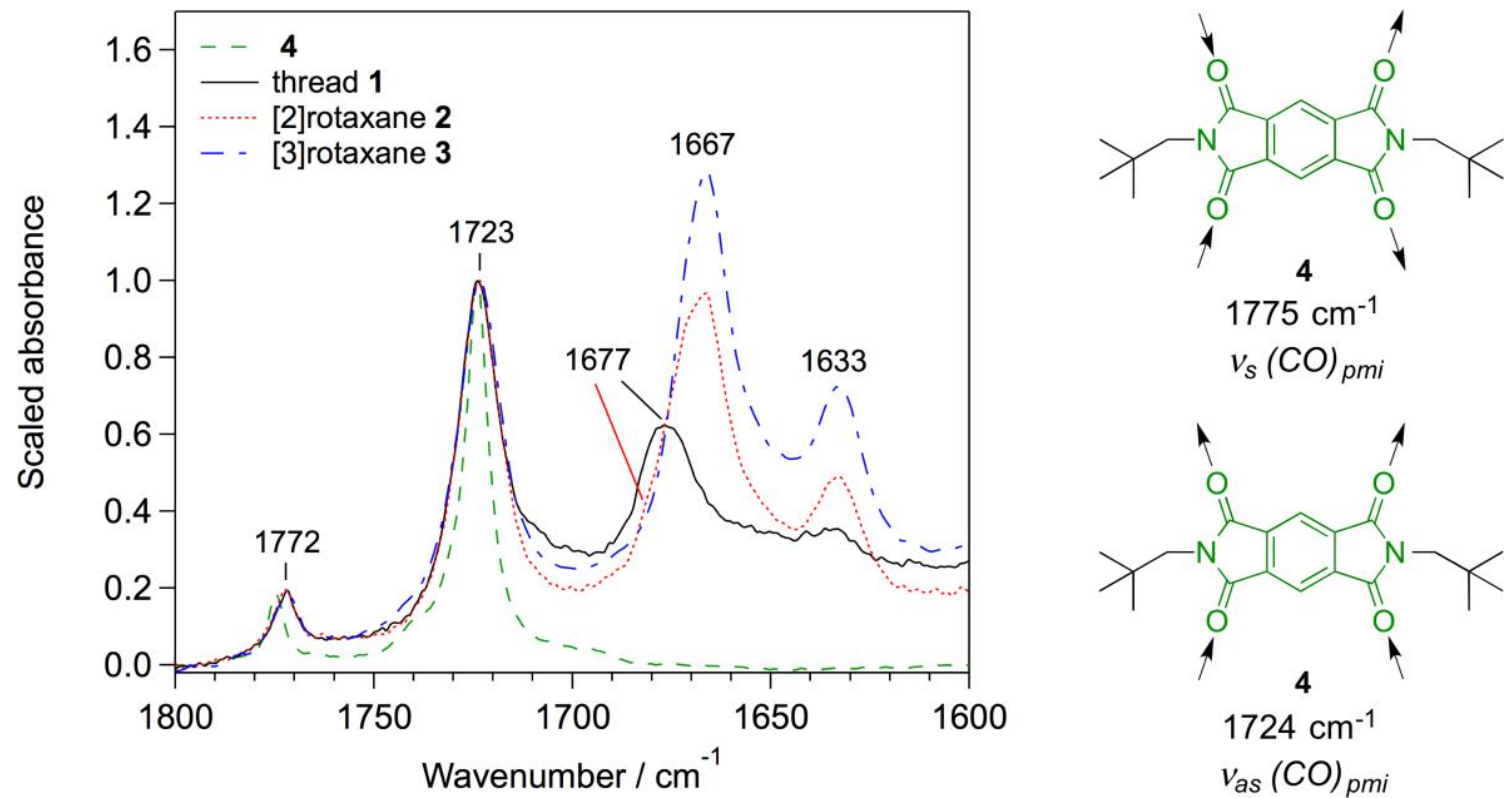

Figure 1 Amide I region in the IR spectra of model compound 4 and pyromellitimide thread $\mathbf{1}$, [2]rotaxane 2 and [3]rotaxane 3 in THF. The spectra were scaled to the intensity of the $v_{a s}(C O)_{p m i}$ band at $\sim 1723 \mathrm{~cm}^{-1}$ in order to facilitate comparison. Vibrational modes and corresponding wavenumbers of the pyromellitimide model compound 4 .

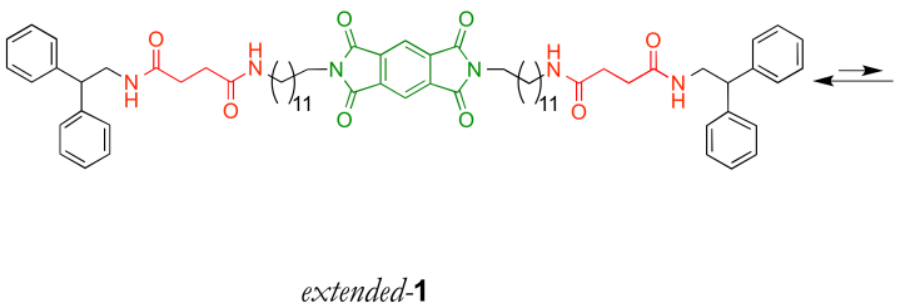

free $v(C O)_{\text {succ }}: 1677 \mathrm{~cm}^{-1}$

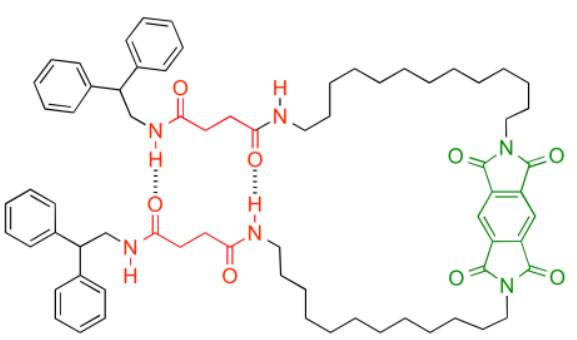

folded 1

H-bonded $v(C O)_{\text {succ }}: 1635 \mathrm{~cm}^{-1}$

Scheme 3 Structures of two possible conformations of thread 1: the predominant extended and the minor folded conformations. 

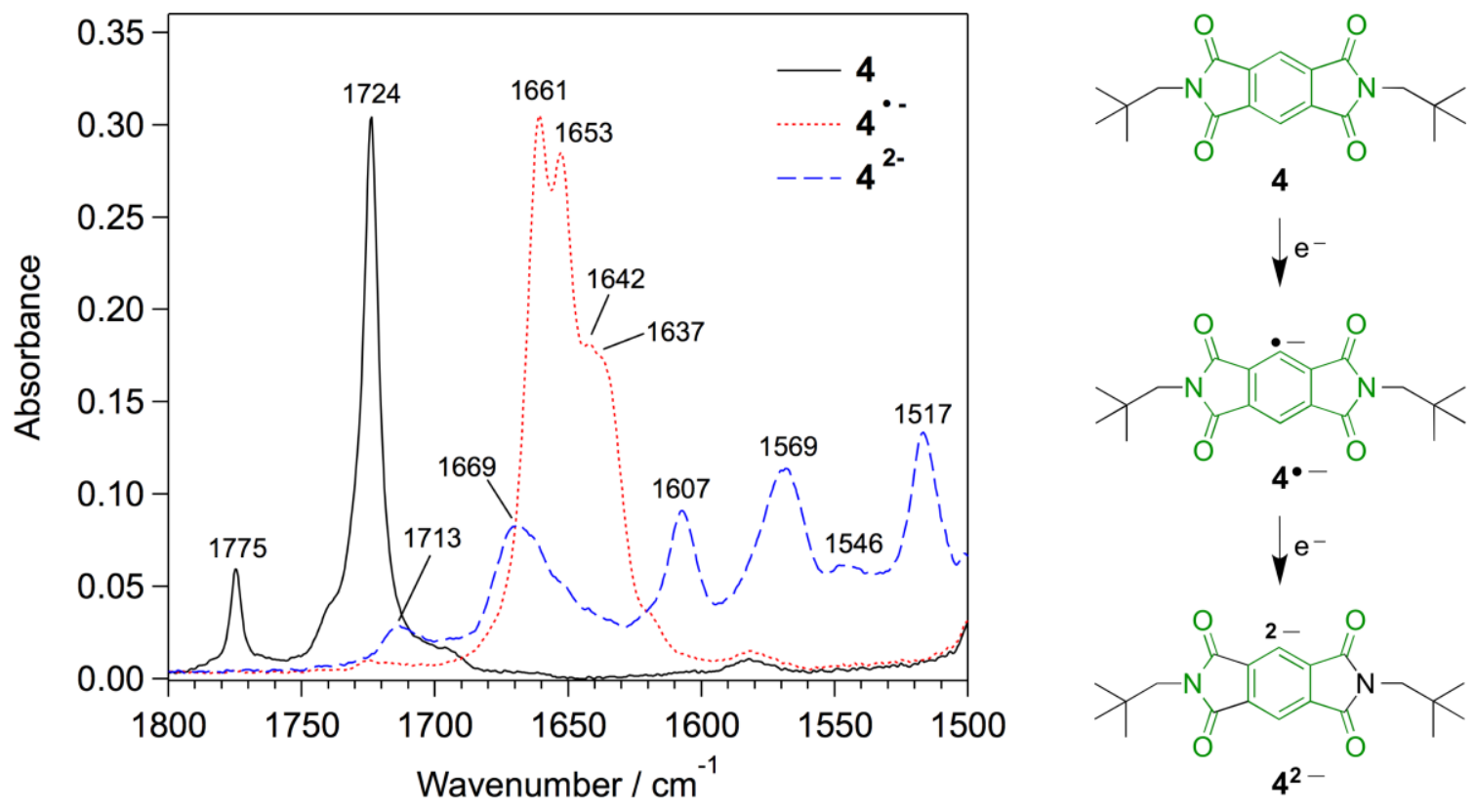<smiles>Cc1c2c(=O)n(CC(C)(C)C)c(=O)c2cc2c(=O)n(CC(C)(C)C)c(=O)c12</smiles>
$4^{\bullet-}$ $\eta^{e}$

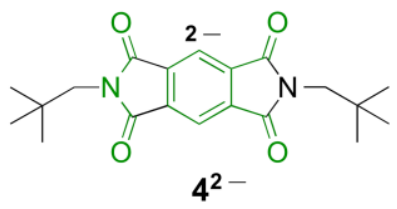

Figure 2 Partial IR spectra of the neutral pyromellitimide model compound 4 ( - ), radical anion $4^{--}(\cdots)$ and dianion $4^{2-}(---)$ in THF. 


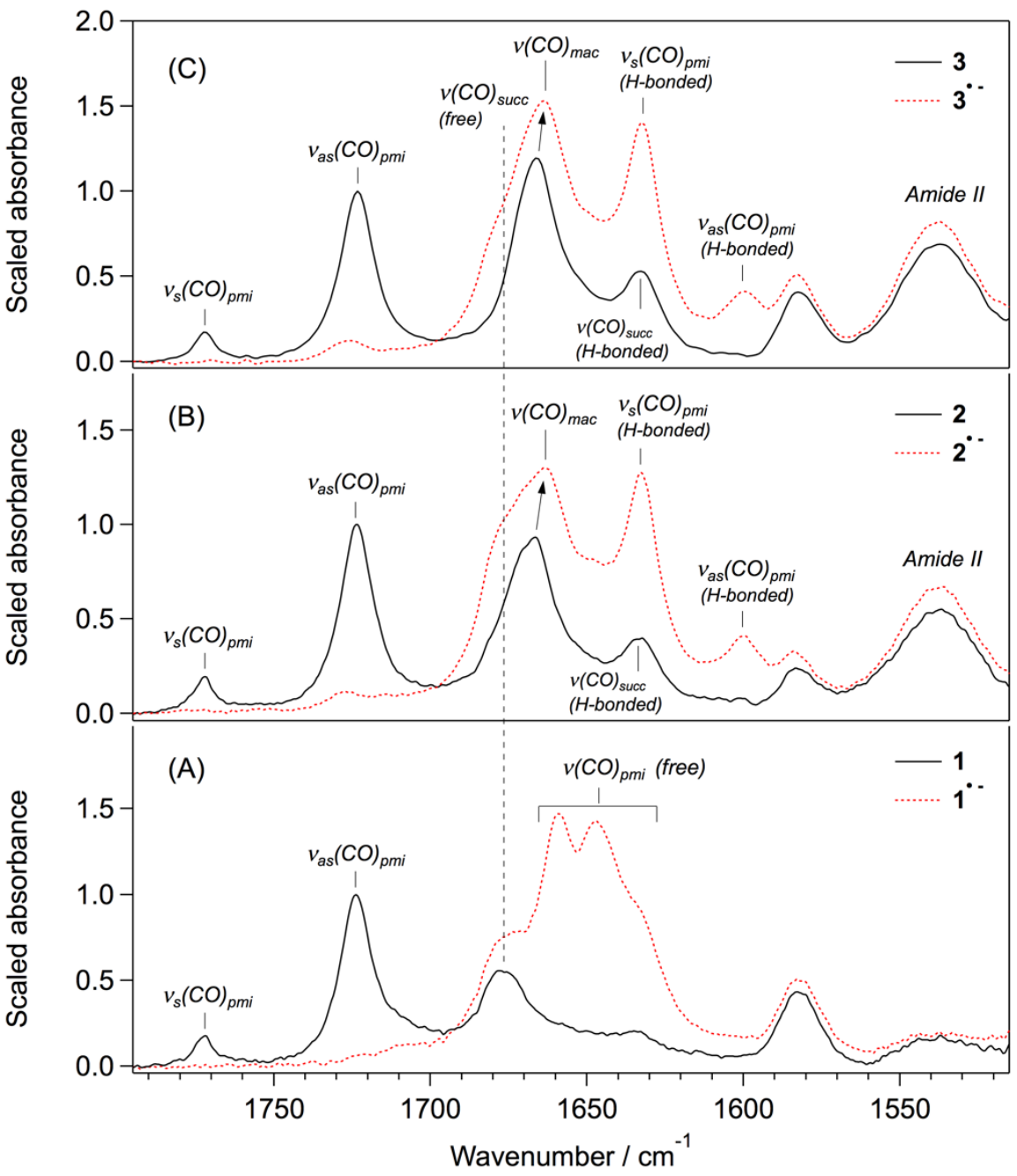

Figure 3 Parts of the IR spectra of neutral $(-)$ and radical anion $(\cdots)$ of $(A)$ pyromellitimide thread 1, (B) [2]rotaxane 2 and (C) [3]rotaxane 3 in THF. The spectra of the neutral species were scaled to the intensity of the $v_{a s}(C O)_{p m i}$ band at $\sim 1723 \mathrm{~cm}^{-1}$. 


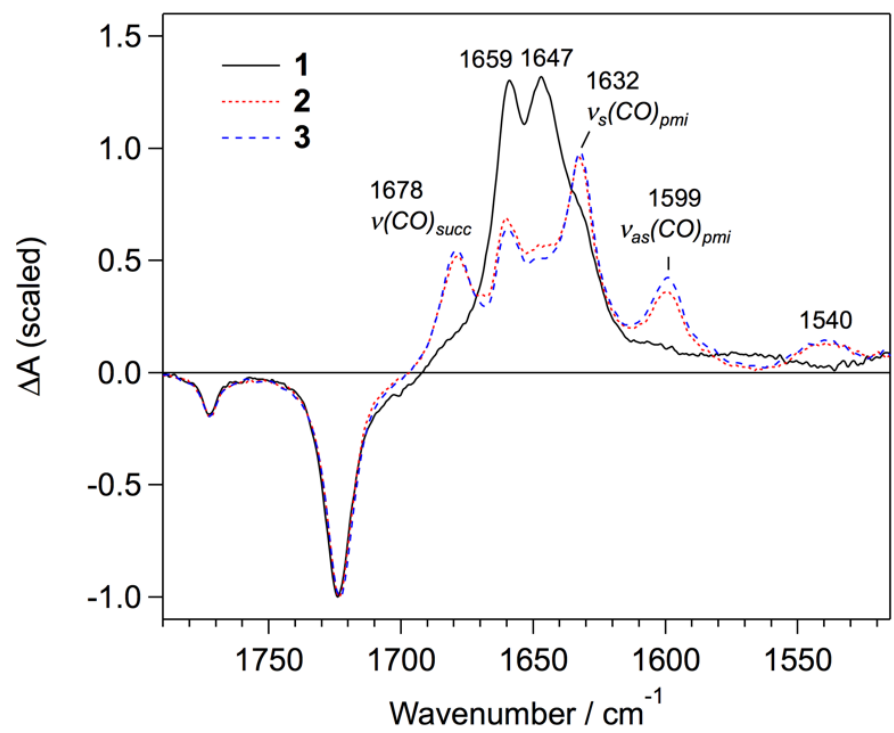

Figure 4 Difference IR spectra (radical anion minus neutral) of thread 1 (一), [2] rotaxane $2(\cdots)$ and [3]rotaxane 3 (- - -) in THF. The spectra were scaled to the intensity of the $v_{a s}(C O)_{p m i}$ band at $\sim 1723 \mathrm{~cm}^{-1}$ before subtraction.

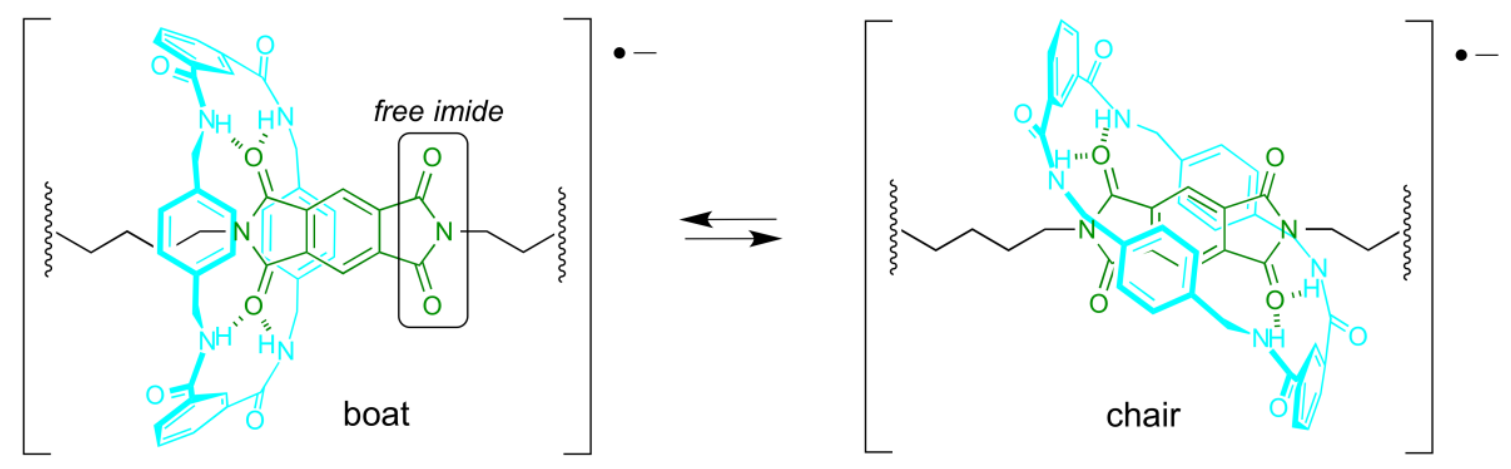

Figure 5 Possible binding modes of the macrocycle to the pmi radical anion in $\mathbf{2}^{\bullet-}$. 

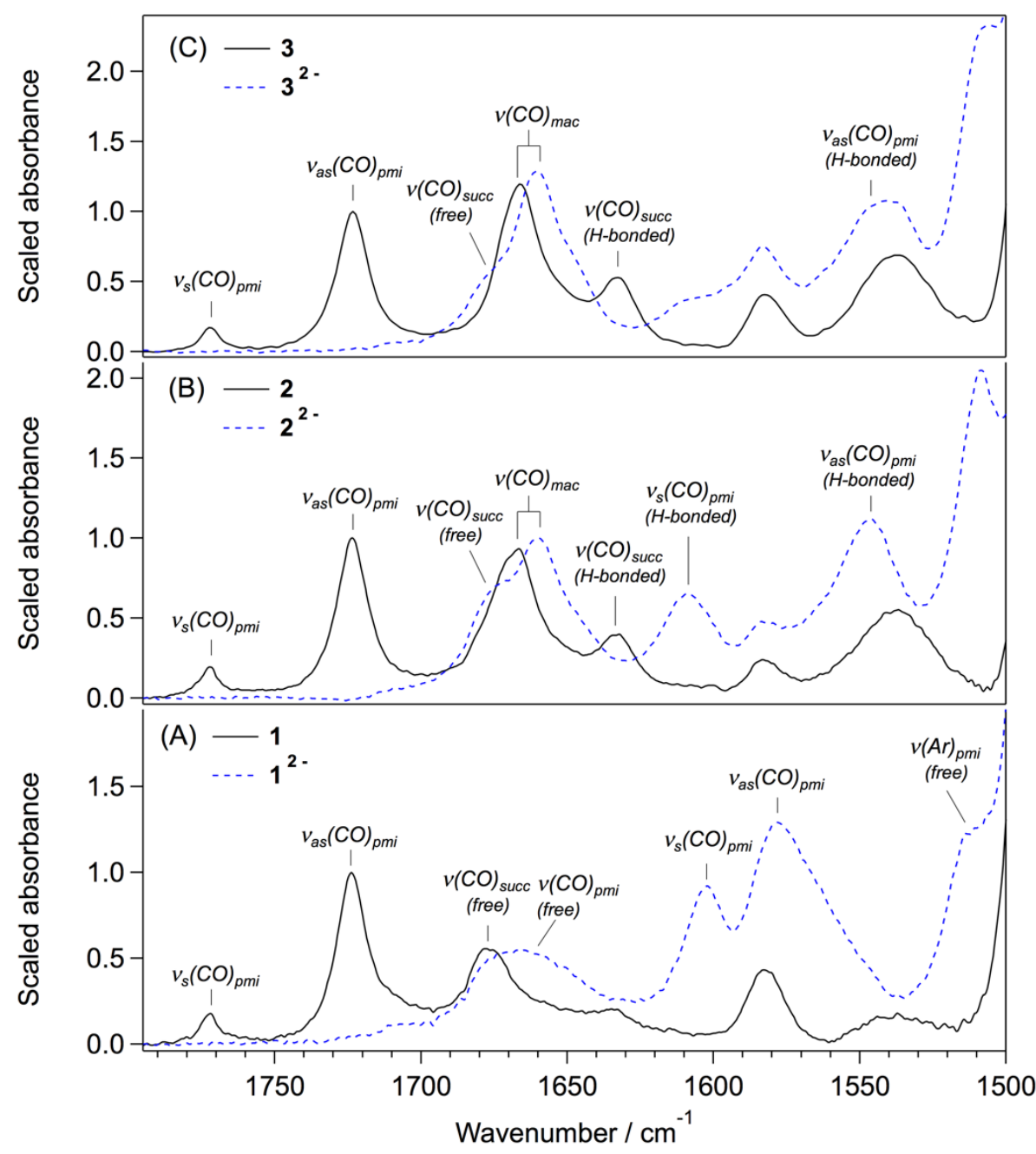

Figure 6 Partial IR spectra of the neutral (-) and dianion (- - ) of (A) pyromellitimide thread $\mathbf{1}$, (B) [2] rotaxane 2 and (C) [3]rotaxane 3 in THF. The spectra were scaled to the intensity of the vas $(C O)_{\text {pmi }}$ band of the neutral species at $\sim 1723 \mathrm{~cm}^{-1}$. The band near $1580 \mathrm{~cm}^{-1}$ is due to the electrolyte. 


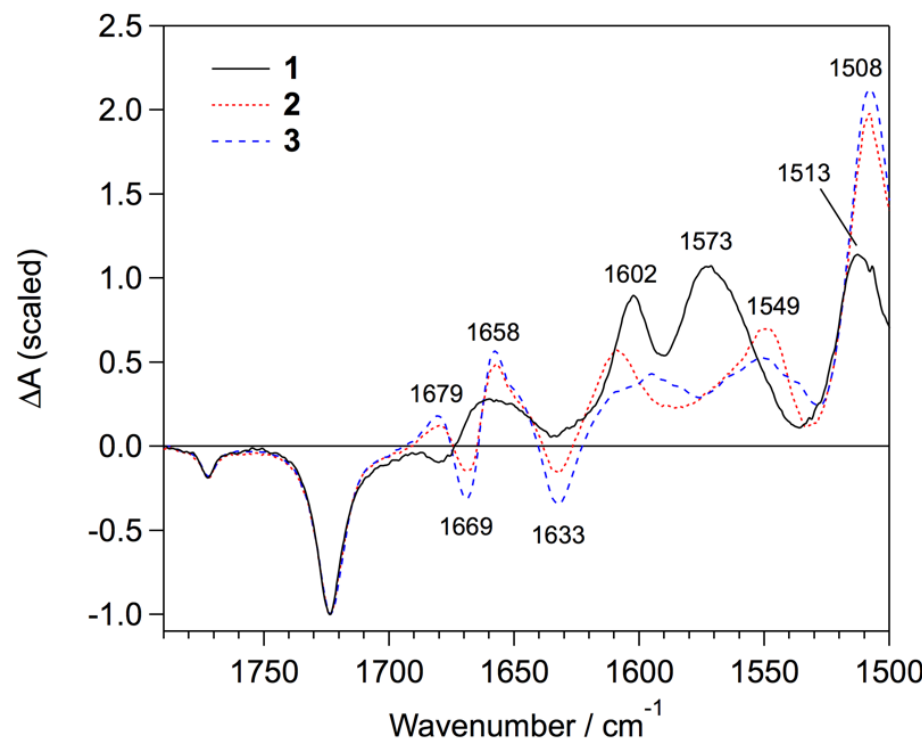

Figure 7 Difference IR spectra (dianion minus neutral) of thread $\mathbf{1}(-)$, [2]rotaxane $2(\cdots)$ and [3]rotaxane $3(--)$ in THF. The spectra were scaled to the intensity of the $v_{a s}(C O)_{p m i}$ band at $\sim 1723 \mathrm{~cm}^{-1}$ before subtraction. 
Table 1 Wavenumbers $\left(\mathrm{cm}^{-1}\right)$ of IR modes in the amide I region of the neutral and radical anions of model compound $\mathbf{4}$, thread $\mathbf{1}$, and rotaxanes 2 and $\mathbf{3}$ in THF.

\begin{tabular}{|c|c|c|c|c|c|c|c|c|}
\hline \multirow[t]{2}{*}{ Mode } & \multicolumn{4}{|c|}{ Neutral } & \multicolumn{4}{|c|}{ Radical anion } \\
\hline & 4 & 1 & 2 & 3 & $4^{\bullet-}$ & $1^{\bullet-}$ & $2^{\bullet-}$ & $3^{\bullet-}$ \\
\hline$v(C O)_{m a c}$ & - & - & 1667 & 1667 & - & - & 1664 & 1664 \\
\hline$v(C O)_{\text {succ }}($ free $)$ & - & 1677 & $1677[\mathrm{a}]$ & - & - & 1677 [a] & $1677[a]$ & $1677[a]$ \\
\hline$v(C O)_{\text {succ }}(\mathrm{H}$-bonded $)$ & - & 1635 & 1633 & 1633 & - & - & - & - \\
\hline$v_{s}(C O)_{p m i}$ & - & - & - & - & $1661[\mathrm{~b}]$ & $1659[\mathrm{~b}]$ & - & - \\
\hline$v_{s}(C O)_{p m i}$ & 1775 & 1772 & 1772 & 1772 & $1653[\mathrm{~b}]$ & $1647[b]$ & 1632 & 1632 \\
\hline$v_{a s}(C O)_{p m i}$ & 1724 & 1723 & 1723 & 1723 & $1642[\mathrm{~b}]$ & $1641[\mathrm{~b}]$ & 1599 & 1599 \\
\hline$v_{a s}(C O)_{p m i}$ & - & - & - & - & $1637[\mathrm{~b}]$ & $1631[\mathrm{~b}]$ & - & - \\
\hline
\end{tabular}

[a] Shoulder on the $v(C O)_{\text {mac }}$ band.

[b] Band splitting due to Fermi resonance (see the text for details).

Table 2 Wavenumbers $\left(\mathrm{cm}^{-1}\right)$ of IR bands in the amide I region of dianions $4^{2-}, \mathbf{1}^{2-}, \mathbf{2}^{2-}$ and $\mathbf{3}^{2-}$ in THF. The wavenumbers were determined from the spectra in Figure 6. Numbers for the neutral systems are the same as in Table 1, and are included to facilitate comparison.

\begin{tabular}{|c|c|c|c|c|c|c|c|c|}
\hline \multirow[t]{2}{*}{ Mode } & \multicolumn{4}{|c|}{ Neutral } & \multicolumn{4}{|c|}{ Dianion } \\
\hline & 4 & 1 & 2 & 3 & $4^{2-}$ & $1^{2-}$ & $2^{2-}$ & $3^{2-}$ \\
\hline$v(C O)_{m a c}$ & - & - & 1667 & 1667 & - & - & 1660 & 1661 \\
\hline$v(C O)_{\text {succ }}($ free $)$ & - & 1677 & $1677^{[a]}$ & - & - & $1677[\mathrm{a}]$ & $1677[\mathrm{a}]$ & $1677[a]$ \\
\hline$v(C O)_{\text {succ }}(\mathrm{H}$-bonded $)$ & - & 1635 & 1633 & 1633 & - & - & - & - \\
\hline n.a. $[\mathrm{b}]$ & - & - & - & - & 1713 & 1709 & 1709 & 1709 \\
\hline n.a. [b] & - & - & - & - & 1669 & 1659 & $\sim 1648$ & $\sim 1648$ \\
\hline \multirow[t]{2}{*}{$v_{s}(C O)_{p m i}$} & 1775 & 1772 & 1772 & 1772 & 1607 & 1602 & $1609[\mathrm{c}]$ & $1609[\mathrm{c}]$ \\
\hline & - & - & - & - & - & - & - & $1595[\mathrm{c}]$ \\
\hline \multirow[t]{2}{*}{$v_{a s}(C O)_{p m i}$} & 1724 & 1723 & 1723 & 1723 & 1569 & 1573 & $1546[c]$ & $1546[\mathrm{c}]$ \\
\hline & - & - & - & - & - & - & - & 1538 [c] \\
\hline n.a. ${ }^{b]}$ & - & - & - & - & 1546 & - & - & - \\
\hline$v(A r)_{p m i}$ & - & - & - & - & 1517 & 1513 & 1508 [c] & 1508 [c] \\
\hline
\end{tabular}

[a] Shoulder on the $v(C O)_{\text {mac }}$ band.

[b] Band could not be assigned as a fundamental.

[c] Hydrogen bonded $\mathrm{C}=\mathrm{O}$. 
Infrared absorption spectroscopy reveals that the two rings in a [3] rotaxane can be successively moved from the peripheral binding stations to the central diimide station upon reduction with one and two electrons, respectively.

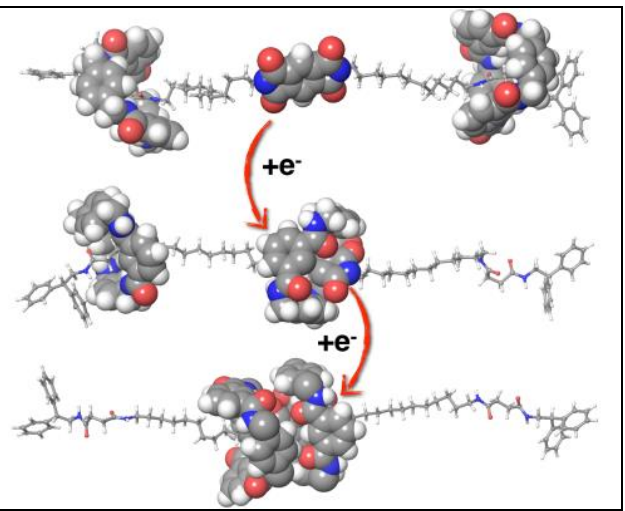

